Chapman University

Chapman University Digital Commons

Economics Faculty Articles and Research

Economics

$12-21-2017$

\title{
Individualism, Collectivism, and Trade
}

Aidin Hajikhameneh

Erik O. Kimbrough

Follow this and additional works at: https://digitalcommons.chapman.edu/economics_articles

Part of the Applied Behavior Analysis Commons, Economic Theory Commons, Other Economics Commons, Other Psychology Commons, and the Work, Economy and Organizations Commons 


\section{Individualism, Collectivism, and Trade}

\section{Comments}

This is a pre-copy-editing, author-produced PDF of an article accepted for publication in Experimental Economics, volume 22, issue 2, in 2019 following peer review. The final publication may differ and is available at Springer via https://doi.org/10.1007/s10683-017-9560-1.

\section{Copyright}

Economic Science Association 


\title{
Individualism, Collectivism, and Trade*
}

\author{
Aidin Hajikhameneh $^{\dagger} \quad$ Erik O. Kimbrough ${ }^{\ddagger}$
}

January 23, 2017

\begin{abstract}
While economists recognize the important role of formal institutions in the promotion of trade, there is increasing agreement that institutions are typically endogenous to culture, making it difficult to disentangle their separate effects. Lab experiments that assign institutions exogenously and measure and control individual cultural tendencies can allow for clean identification of these effects. We focus on cultural tendencies toward individualism/collectivism, which social psychologists highlight as an important determinant of many behavioral differences across groups and people. We design an experiment to explore the relationship between subjects' dispositions to individualism/collectivism and their willingness to engage in impersonal trade under enforcement institutions of varying strength. Overall, we find that individualists tend to engage in trade more often than collectivists. This effect is mitigated somewhat as the effectiveness of enforcement institutions increases. That is, the detrimental impact on future trade of having been cheated in the past is reduced. Nevertheless we see that cultural dispositions shape the decision to engage in impersonal trade, regardless of institutional environment.
\end{abstract}

JEL classifications: $C 7, C 9$

Keywords: individualism, collectivism, exchange, trust, experiments

\footnotetext{
${ }^{*}$ The authors thank the Social Science and Humanities Research Council of Canada and the Teaching and Learning Centre at Simon Fraser University for financial support. We would also like to thank Tanya Broesch, Greg Dow, David Freeman, David Jacks, Laurence Iannaccone, Michael McBride, Angela de Oliviera, Rob Oxoby, Jared Rubin, John Spraggon, and audiences at the 2015 Economic Science Association North American meeting, 2016 Association for the Study of Religion, Economics and Society Annual Conference, and the University of Massachusetts-Amherst Behavioral and Experimental Economics Reading Group for helpful comments. Figures were created using the open-source statistical software R.

${ }^{\dagger}$ Corresponding Author: Institute for the Study of Religion, Economics and Society, Chapman University, $338 \mathrm{~N}$. Glassell, Orange, CA 92866, USA, e-mail: hajikhameneh@chapman.edu

‡Department of Economics, Simon Fraser University, 8888 University Drive, Burnaby, BC V5A 1S6, Canada, e-mail: ekimbrou@sfu.ca
} 
The core element of individualism is the assumption that individuals are independent of one another.

$[\ldots]$

The core element of collectivism is the assumption that groups bind and mutually obligate individuals.

$\sim$ (Oyserman et al., 2002, p. 5, emphasis added)

\section{Introduction}

Economists have long emphasized the crucial role of strong formal institutions in facilitating trade (e.g. North, 1990). In particular, the transition from personal, small-scale exchange to impersonal, large-scale trade is believed to rely on the development of contract enforcement institutions that facilitate trade by reducing the incentive to cheat. Starting with Greif (1994) they have also explored how cultural variables may influence the development of long-distance trade. One line of research has focused on how cultural dispositions to individualism and collectivism influence the means by which parties solve the "fundamental problem of exchange", that of contract enforcement (Greif, 2000). Here we study the relationship between individualism/collectivism and the willingness to seek trade opportunities in the first place.

As Triandis (2001) notes, "the individualism/collectivism cultural syndrome appears to be the most significant cultural difference [between societies]". One crucial distinguishing feature of individualists and collectivists is how they view their relationships with others. Individualists are believed to value relationships instrumentally, "[balancing] relationships' costs and benefits, leaving relationships and groups when the costs of participation exceed the benefits and creating new relationships as personal goals shift" (Oyserman et al., 2002, p. 5). Collectivists are believed to value their relationships intrinsically, implying "that (a) important group memberships are ascribed and fixed, viewed as 'facts of life' to which people must accommodate; (b) boundaries between in-groups and out-groups are stable, relatively impermeable, and important; and (c) in- 
group exchanges are based on equality or even generosity principles" (Oyserman et al., 2002, p. 5). These differences may have implications for individuals' willingness to initiate long-distance trade. ${ }^{1}$

Local, personal exchange is a fact of human life, but the transition to long-distance, impersonal exchange often involves severing (or weakening) ties to local trade partners in order to form new, potentially more lucrative, ties with an unknown party from elsewhere. This implies that, even with effective institutions, there may be differences in the willingness of individualists and collectivists to embrace new trade opportunities. Because collectivists value their relationships intrinsically, they may effectively incur an additional cost when abandoning an existing relationship to seek a new trading partner. We hypothesize that this is one of the channels through which collectivism may dampen the willingness to engage in long-distance trade.

In this paper, we report an experiment in which "farmers" may break off a pre-existing, mutually beneficial exchange relationship with a "local merchant" in order to seek a potentially more lucrative exchange with a stranger ("traveling merchant"), and we compare the behavior of individualistic and collectivistic people who are faced with this choice under different institutional arrangements. Subjects in our experiment interact in a "narrativized" trust game which employs narrative context to induce a pre-existing relationship and embed the decisions in a relevant historical context (Osborn et al., 2015). As Kuran (2010) notes, the primary mode of long distance exchange in the pre-modern era involved "a sedentary and passive investor along with active laborer or traveling merchant" (p. 66). Greif (2000) points out that such a relationship is readily modeled as a trust game (e.g. Berg et al., 1995).

In the narrative, a "farmer" initially faces the (trivial) choice between autarky and risk-free, mutually beneficial exchange with a local partner. After four rounds of local trade, the farmer is

\footnotetext{
${ }^{1}$ Crucially, while individualism and collectivism are often conceived at the societal level (e.g. Hofstede, 1980), psychologists recognize these dispositions as personal traits, such that each person lies somewhere on a continuum from purely individualistic to purely collectivistic (Triandis, 1995). Triandis, in this book, coined the terms idiocentrism and allocentrism for individual-level analysis of individualism and collectivism. In this paper, however, we use the more familiar terms individualism and collectivism. Understanding individualism and collectivism as individual traits means that we can measure subjects' dispositions to individualism/collectivism and correlate them with decisions in an experiment.
} 
approached by a "traveling merchant" who offers to take the farmer's goods and sell them in a foreign market for a tidy profit. If the farmer chooses this option, the merchant may complete the contract or cheat and keep all the profits for himself. Crucially, trading with the traveling merchant necessarily implies abandoning the relationship with the local trade partner, leaving him in autarky. Given the incentive structure of the game, which involves no repeat interaction between farmers and traveling merchants, the subgame perfect Nash equilibrium (SPNE) for risk-neutral, payoff-maximizing agents involves only local trade.

In three experimental treatments, we vary the availability of an exogenous, formal contract enforcement mechanism: a court, in which cheating merchants are punished probabilistically. In the baseline No Enforcement (NE) treatment, there is no court. In the Weak Enforcement (WE) treatment, the court exists but punishes cheaters with a low probability such that trade is still not incentive compatible in the SPNE. In the Strong Enforcement (SE) treatment, punishment is sufficiently likely that the farmer trades in equilibrium, even though the merchant still cheats.

In each of these treatments, we compare the behavior of individualistic and collectivistic farmers. We follow Talhelm et al. (2014) who developed a measure of individualism and collectivism (hereafter, I/C score) that relies on simple choice problems to reveal differences in individual cognition, that are known to be correlated with cultural dispositions to collectivism and individualism.

As noted above, due to the external cost imposed on local merchants, collectivist farmers may be less inclined to trade with traveling merchants. Another channel through which individualism/collectivism tendencies may affect long-distance trade is through collectivists' focus on group-level, rather than individual-level characteristics. Collectivists tend to perceive individuals from a group as interdependent. If collectivist farmers understand traveling merchants to be members of the same group, then an act of cheating by one traveling merchant may be perceived as reflecting a group characteristic. Thus, when cheated once, collectivists may be more likely to be deterred from trade in the future.

Implementation of formal enforcement mechanisms is orthogonal to the collectivistic traits 
that dampen the probability of engaging in long-distance trade. In all treatments, long-distance trade involves abandoning an existing relationship with the local merchant, and in the SPNE, the farmer will be cheated with probability 1 . Therefore, we expect that collectivist farmers engage in long-distance trade significantly less often than individualist farmers across the NE, WE and SE treatments.

In a robustness check designed to investigate the effect of the external cost imposed on local merchants by farmers' trade decisions, we eliminate the role of the local merchant in the NE treatment (we call this the NoLM treatment). As a result, there is no external cost imposed on the local merchant, so if this cost hindered trade among collectivists in the NE treatment, the differences between collectivists and individualists should weaken or disappear.

In two further robustness checks, we probe the underlying cultural norms that affect longdistance trade by conducting incentivized norm- and belief-elicitation tasks. In the norm elicitation task, we look for the difference in the perceived social appropriateness of each of the farmers' possible actions across the individualism/collectivism spectrum. If individualists view abandoning trade with the local merchant as simply less wrong than collectivists, this may account for observed treatment differences. In a similar vein, in the belief elicitation task, we investigate the possibility that individualistic and collectivistic farmers have heterogeneous beliefs about the probability of reciprocation by traveling merchants. This will allow us to determine if differences in behavior are driven by cultural differences in beliefs about the likelihood of reciprocation by the traveling merchant (a stranger).

Our findings suggest that individualist farmers are more likely to trade with traveling merchants than collectivist farmers in the NE, WE, and SE treatments. However, we observe no significant difference in long-distance trade between individualists and collectivists in the first period that trade is possible. This indicates that the effect of the negative externality alone is not strong enough to deter collectivist farmers from engaging in long-distance trade. Cheating, understandably, has significant negative effect on future long-distance trade. Collectivists, though, drop out of long-distance trade significantly more often, after being cheated. This ef- 
fect, while significant, weakens as the court becomes stronger. That is, a stronger court system mitigates the effects of cultural dispositions. In the NoLM treatment, long-distance trade is not statistically distinguishable between collectivists and individualists. That is, reversion to local trade after being cheated by collectivist farmers seems to be partially motivated by the external cost imposed on the local merchant. In the belief elicitation task, we find that individualist farmers are significantly more optimistic regarding the probability of traveling merchants' reciprocation than collectivist farmers. This partially explains why individualist farmers engage in the long-distance trade more often that their collectivist counterparts regardless of enforcement mechanisms.

\subsection{Related Literature}

As in Fehr (2009), we argue that heterogeneous preferences and beliefs explain differences in the willingness to engage in trade, but we tie this heterogeneity to underlying differences in collectivism and individualism. Collectivists and individualists differ in their preferences over the external cost imposed by trade on local merchants, and in how they update their beliefs after being cheated. Many previous experiments have attempted to measure differences in preferences related to trust and trade (e.g. McCabe et al., 2003; Cox, 2004; Cox and Deck, 2005). In previous experiments, the belief channel has been explored mainly through implementation of either an individual or a group reputation system. Studies have shown that individual reputation systems induce cooperative behavior in repeated trust games (Bernhard et al., 2006; Bohnet et al., 2005; Bohnet and Huck, 2004; Charness et al., 2011). In the same vein, Cassar et al. (2010) used a continuous double auction setup to compare trade behavior in a known-identity "local" versus an anonymous "distant" market. They find that sharing individual reputation information significantly dampens cheating. Healy (2007) shows how the logic of sustaining cooperation via individual reputation (e.g. Kreps et al., 1982) can be extended to group reputation, so that in the presence of Pareto-improving cooperative outcomes and an inferior equilibrium, cooperation can be sustained until the penultimate period of a finitely repeated game. Recent experiments 
suggest that group reputation information either encourages cooperative behavior (Huck and Lünser, 2010) or creates path-dependence (Kimbrough and Rubin, 2015). There is no reputation system in our design per se; however, the aforementioned heterogeneity in belief updating after being cheated may be interpreted as collectivist farmers assigning traveling merchants a group reputation.

The link between risk preferences and trust or engaging in long-distance trade is also related to our experiment. Most research on this subject showed that trust and risk are independent (Eckel and Wilson, 2004; Houser et al., 2010); however, there are some evidence that risk preferences can partially explain trust (Schechter, 2005; Karlan, 2005). In a cross country study, Bohnet et al. (2008) compared the minimum accepted probability of reciprocation for player 1 to enter into trades in trust games in which player 2 was either a human or a lottery. The minimum accepted probability in the lottery treatment would offer a risk preferences measure while in the human player 2 the probability includes the trust factor. They find that in all countries, minimum accepted probability is significantly higher in the human treatment suggesting trust cannot be completely explained by risk preferences. Our results show that risk-preferences are not significant determinants of trade in the NE, WE, and SE treatments. In the NoLM treatment, however, risk attitude is marginally significant. This suggests that risk is not a primary concern of collectivist farmers.

Finally, previous studies of the trust game reveal considerable heterogeneity across subjects within a given treatment (see e.g. Johnson and Mislin, 2011, for a summary), and our design may contribute to the explanation of some of that variation via cultural differences across individuals.

\section{Experimental Design, Procedures and Hypotheses}

To investigate how cultural dispositions affect the decision to engage in impersonal exchange, we study a repeated modified trust game (henceforth RMTG) that captures the important features of the problem faced by prospective traders in history. In the experiment, the RMTG has 
been narrativized to mimic the historical context in which long-distance trade occurred during the Middle Ages. Subjects, depending on their role and decision, see an interactive screen in which the complete information regarding different decision paths is given, along with a narrative context meant to reinforce certain design elements. See appendix A for full instructions.

A subject plays one of three roles in the economy: farmer, local merchant, or traveling merchant. The farmer sells her products through either a local merchant or a traveling merchant. The narration portrays the local merchant as a trustworthy person with whom the farmer has a long-standing relationship. The traveling merchant offers a higher possible payout; however, he can abscond with the farmer's money.

In addition to the narration, to induce a relationship between the farmer and the local merchant in the lab, the first four periods of the game involve interactions between only the farmer and the local merchant. This portion of the game is the same across treatments; hence, we refer to it as the common stage. In the common stage, the farmer faces a trivial decision between 'Autarky', which yields a payoff of $A$ for everyone, or risk-free 'Local Trade' with the local merchant, which yields a payoff of $2 A$ for both the farmer and the local merchant. Traveling merchants are dormant at this stage of the game, and regardless of the farmer's decision, their payoff is $A$. The extensive form of the RMTG common stage is depicted in the upper left portion of figure 1. The top, middle, and bottom payoffs correspond to the farmer, local merchant, and traveling merchant, respectively.

After the common stage, in each of periods 5-8, a traveling merchant arrives in the farmer's village and offers to take the farmer's product and sell it on the foreign market. The farmer still has access to the local market which provides a guaranteed payment of $2 A$ to the farmer and local merchant and ensures the traveling merchant gets $A$. If instead the farmer chooses 'Foreign Trade', he abandons his relationship with the local merchant (guaranteeing him a payoff of $A$ ) and allows the traveling merchant to sell his goods abroad, creating a surplus of $8 A$, which may be shared by the farmer and the traveling merchant. The traveling merchant then decides whether to 'Share' or 'Steal'. If he chooses 'Share', the game ends and the farmer and the travel- 


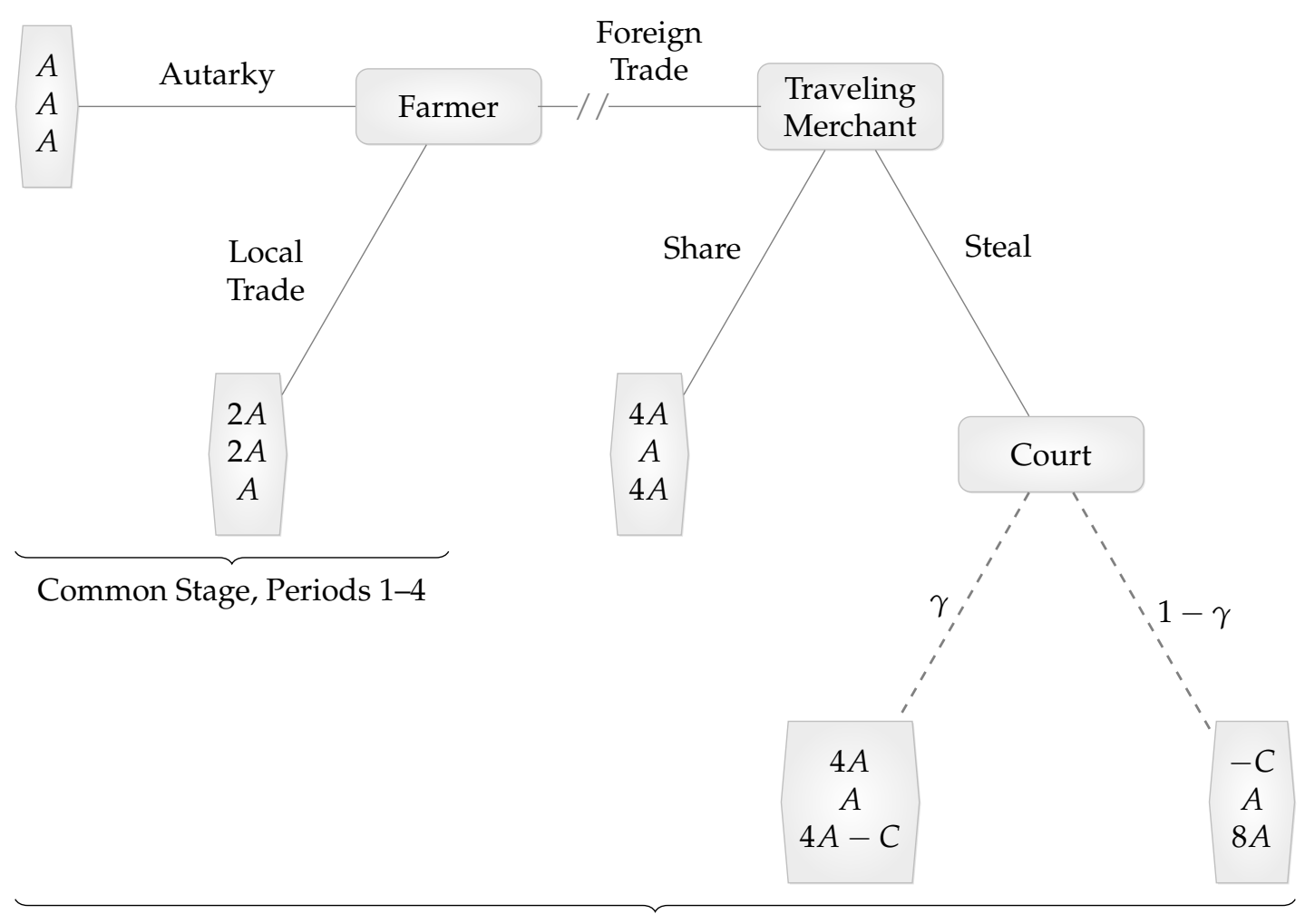

Treatment Stage, Periods 5-8

Figure 1: Repeated modified trust game

ing merchant each receive $4 \mathrm{~A}$. If he chooses 'Steal', the traveling merchant takes the entire $8 \mathrm{~A}$. However, we have incorporated the idea of a judicial system into the RMTG via a court apparatus which catches the cheating merchant with probability $\gamma$ and forces him to complete the contract. Appeals to the court impose a litigation $\operatorname{cost} C$ which is paid by the farmer if he loses and by the traveling merchant if he wins. This information is summarized in the right portion of figure 1.

Given these payoffs, for risk-neutral, money-maximizing merchants, choosing 'Steal' is optimal whenever $\gamma \leq \frac{4 A}{4 A+C}$, and a risk-neutral, money-maximizing farmer's optimal strategy is to engage in local trade whenever $\gamma \leq \frac{2 A+C}{4 A+C}$.

An essential feature of our design is that we must measure our subjects' propensities for individualism and collectivism prior to participating in the experiment because we assign the most and least collectivistic individuals to the role of "farmer" in our narrative. This ensures that 
we have sufficient variation in I/C propensities in the subjects making the decisions of interest, but it also requires careful thought about how to measure I/C propensity efficiently while also minimizing the risk of spillovers into experimental behavior.

\subsection{Measuring individualism and collectivism}

Following the seminal study of individualism and collectivism by (Hofstede, 1980), various scholars have created different methods to measure these cultural traits. These methods, in general, can be divided into two categories; questionnaires and cognitive tests. Triandis and his colleagues utilized the questionnaire method (Hui and Triandis, 1986; Triandis et al., 1990; Triandis, 1995). In this approach, people are to answer how they would act, behave, or think in a series of different situations. For example,

"You are about to make an important decision (e.g. marriage, career choice). How often you are likely to spend time considering the implications of the decision (e.g. economic, emotional) on your relatives [friends, neighbors, etc]? 1=all the time; $5=$ never".

In these questionnaires collectivism is identified with responses indicating more consideration of the perspectives of local in-groups when making important personal decisions. Individualism, on the other hand, is identified with responses indicating that the respondent is less likely to take the perspectives of others into account.

Since the role assignment protocol in this experiment is based on the subjects' dispositions to individualism and collectivism, we have to measure their individualism/collectivism tendencies

prior to the treatments. Thus, we require an elicitation technique that avoids the risk of priming subjects in a manner that would influence their decisions in our treatments. This would have been a real concern if we asked subjects to think about their relationship with in-group members immediately before they play the game involving tradeoffs between the local merchant and the traveling merchant. Hence, we eschewed the questionnaire method. 
Nisbett et al. (2001) argued that cognitive orientations are influenced by "the considerable social differences that exist among different cultures". According to this work, e.g., people of the East Asian origin tend to have a "holistic" view of the world, "attending to the entire field and assigning causality to it" while people of the Western European origin ${ }^{2}$ tend to have an analytic view, "paying attention primarily to the object and the categories to which it belongs and using rules" (p. 291).

The cognitive test method of measuring cultural differences attempts to measure these cognitive tendencies. One prominent example due to Kitayama et al. $(2003,2009)$ is known as the "framed-line task". In the first stage of this task, subjects see a square with a line inside it. In the next stage, they see an empty square which might be larger, smaller, or the same size as the original square. They repeat this task for a limited number of times with one of the following instructions: draw a line which is the same length as the original line (that is, absolute task) or draw a line that has the same relative proportions as the original line (that is, relative task). The authors argue that the analytic minded subjects should perform better in the absolute task since this "task requires attention to be focused on the target line" while holistic minded subjects should perform better in the relative task since it "requires attention to be allocated broadly to both the target line and the surrounding square"(Kitayama et al., 2009, p. 242). Initial results from this task showed that American subjects are more analytic minded compared to Japanese subjects. However, Hakim et al. (2016) replicated the framed-line task for a larger sample than Kitayama et al. (2003) using computers for measurement. They also have measured the lines in pixels compared to millimeters in the original study, and they found no significant visual cognition difference between American and Chinese subjects.

The implicit focus of the questionnaire method on the externality imposed on family, friends, and in-group members along with the inconsistent results of the framed-line task propelled us to employ another prominent cognitive test, known as the "Triad Task" (Chiu, 1972; Ji et al.,

\footnotetext{
${ }^{2}$ In numerous cross-country studies, scholars have found that people of East Asian origin (for example, Japan, China, and South Korea) have collectivistic tendencies while people of Western European origin (for example, United States and Germany) exhibit individualistic tendencies (Schwartz, 1992; Triandis et al., 1988; Green et al., 2005).
} 
2004; Talhelm et al., 2014, 2015). In this task, subjects answer 20 questions in which they are required to choose the two words from a list of three that are "most closely related". Of the 20 questions, 8 are scored and used to construct the I/C score and 12 are filler questions designed to limit any pattern recognition by subjects. Here is an example of a scored question: "Of the following three things, please indicate which two of the three are most closely related: train, bus, tracks." This is a cognitive test in which individualists are inclined to match on category (train and bus); while, collectivists are inclined to match on relationship (train and tracks). Thus, the task measures a propensity to holistic vs. analytical thinking, which are, respectively, associated with collectivism and individualism:

Psychologically, growing up in an individualistic social world biases one toward the use of analytical reasoning, whereas exposure to more collectivistic environments favors holistic approaches. Thinking analytically means breaking things down into their constituent parts and assigning properties to those parts. Similarities are judged according to rule-based categories [...]. Holistic thinking, by contrast, focuses on relationships between objects or people anchored in their concrete contexts. Similarity is judged overall, not on the basis of logical rules.

(Henrich, 2014, p. 593).

In their study of Chinese farmers from two regions, Talhelm et al. (2014) showed that responses to the Triad Task are correlated with collectivistic and individualistic production processes (rice vs. wheat farming) at the individual and societal level. Thus, we are comfortable using this proxy for an individual's underlying degree of collectivism. Importantly, we hypothesize that the relational perspective that underlies holistic thinking applies equally to human relationships, such as that between the farmer and the local merchant in our experiment, and the relationship between the categorical matching of train and tracks in the above example.

After subjects complete the Triad Task, we assign a score of 1 for each individualistic response and a score of -1 for each collectivistic response. We refer to the normalized sum of these scores as the individualism/collectivism score (henceforth I/C score, see appendix A.3 for the full task). 
The advantages of this task are threefold. First, according to Talhelm et al. (2014), it captures the difference in the cognitive orientations successfully. Second, the abstract nature of this task eliminates the priming effect. Third, it can be conducted in a short amount of time with a high accuracy.

\subsection{Procedures}

Upon arriving to the lab, subjects first complete the Triad Task due to Talhelm et al. (2014), which provides a measure of their I/C score. The two most collectivistic and the two most individualistic subjects in a session were assigned the role of farmers; this ensures that we have sufficient variation in I/C score among subjects participating in the role of farmer. The remaining eight subjects were randomly assigned to be either a local merchant or a traveling merchant, so that each session has four farmers, four local merchants and four traveling merchants.

After role assignment, subjects begin the narrative of the RMTG. They first play 4 periods of the Common Stage and then 4 periods of the Treatment Stage in a single treatment. Across all treatments, we set $A=4$. Our treatments vary the court enforcement power $\gamma$ and the cost of litigation $C$. In the No Enforcement (NE) treatment, the court enforcement power and litigation costs are zero. In the Weak Enforcement (WE) treatment, $\gamma=0.5$ and $C=5$ so that, while there is a positive probability of the court enforcing the contract, the probability is low enough that choosing 'Foreign Trade' is still a dominated option $\left(0.5<\frac{2 A+C}{4 A+C}<\frac{4 A}{4 A+C}\right)$. This treatment allows us to test whether the the addition of court per se, even when it is ineffective, induces different responses by individualists and collectivists. In the Strong Enforcement (SE) treatment, $\gamma=0.7$ and $C=5$. In this treatment, court enforcement is strong enough to induce money-maximizing farmers to choose 'Foreign Trade' while still inducing traveling merchants to choose 'Steal' $\left(\frac{2 A+C}{4 A+C}<0.7<\frac{4 A}{4 A+C}\right)$.

Finally, in a fourth treatment designed to test the robustness of our interpretation and to ensure that our narrative successfully induces a relationship with the local merchant, we remove the human local merchant from the game, so that foreign trade no longer imposes a negative 
externality (we call this the NoLM treatment). This game reduces to a trust game with the addition of a third dominated action (Autarky). We discuss this treatment in more detail in section 3.4 below. Table 1 summarizes the experimental design and the SPNE for money-maximizing agents.

\begin{tabular}{lcccccccc}
\hline & \multicolumn{9}{c}{ Parameters } & \multicolumn{2}{c}{ SPNE } & \multicolumn{2}{c}{ Data } \\
\cline { 2 - 8 } & $A$ & $\gamma$ & $C$ & Trade & Cheat & Sessions & Subjects/Session \\
\hline No Enforcement (NE) & 4 & 0 & 0 & no & yes & 4 & 12 \\
Weak Enforcement (WE) & 4 & 0.5 & 5 & no & yes & 4 & 12 \\
Strong Enforcement (SE) & 4 & 0.7 & 5 & yes & yes & 4 & 12 \\
No Local Merchant (NoLM) & 4 & 0 & 0 & no & yes & 4 & 8 \\
\hline
\end{tabular}

\section{Table 1: Summary of experimental treatments}

Our matching scheme is a combination of partner matching (between farmers and local merchants) and perfect stranger matching (between farmers and traveling merchants). Throughout the game, the farmer is partner matched with a local merchant, but in each round of the Treatment Stage, the farmer is matched with a new traveling merchant. The narration emphasized that farmers were trading with "a new merchant" and that merchants were trading in "another village". The matching scheme is depicted in figure 2 .

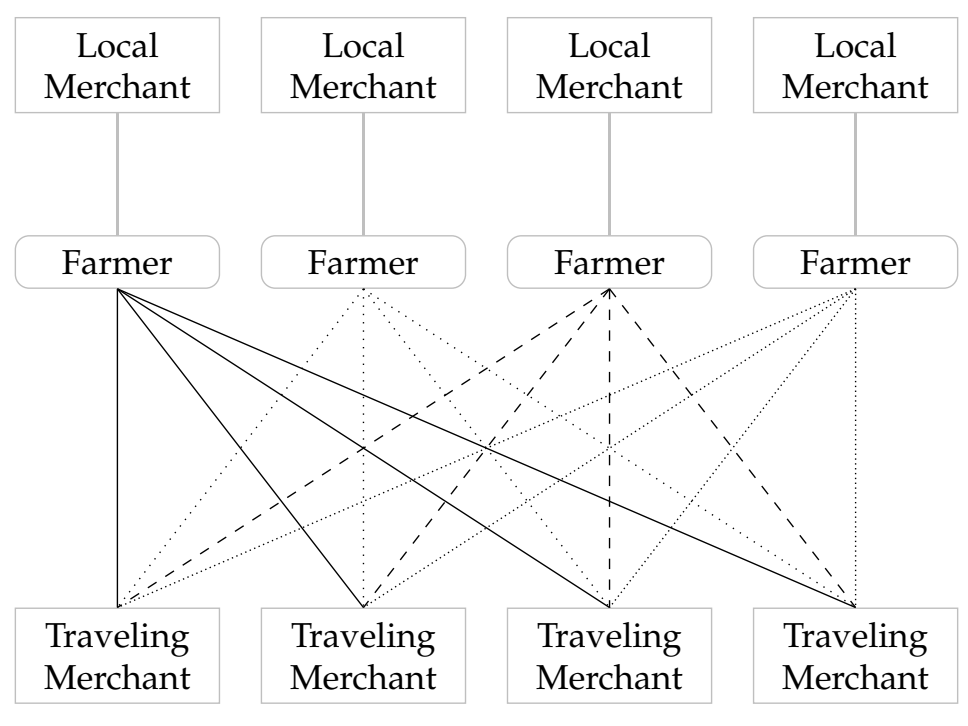

Figure 2: Matching protocol 
Following this matching scheme, the experiment ends after 8 periods of the RMTG. Since risk-preferences may influence the decision to engage in long-distance trade, independent of individualism and collectivism, at the end of the session, we elicited subjects' risk preferences using a multiple price list mechanism based on Holt and Laury (2002). Subjects faced a sequence of ten choices between two lotteries. Lottery 1 had a constant 0.5 probability of paying either $\$ 1$ or $\$ 3$ while lottery 2 (over $\$ 0.1$ and $\$ 4$ ) had an increasing probability of paying $\$ 4$ in the sequence. One choice was drawn at random and paid for each subject. The full set of lotteries and the instructions can be found in appendix A.4. We use the number of times the subject chose lottery 2 as a measure of risk preference.

The experiment included 16 sessions, 4 per treatment. In each session of the NE, WE and SE treatments, 12 subjects participated, and in each session of the NoLM treatment, 8 subjects participated, for a total of 176 subjects. Experiments were conducted at Simon Fraser University between February and June 2015, and the software was developed using zTree (Fischbacher, 2007). At the end of the session, the subjects' total ECU from all 8 periods were summed and converted to $\mathrm{CAD}$ at a rate $12 \mathrm{ECU}=\$ 1$. Then we added the earnings from the risk-preference elicitation. The payment range was from $11 C A D$ to $22 \mathrm{CAD}$ including a $7 \mathrm{CAD}$ show-up fee. Subjects were recruited for sessions lasting 1 hour, but in practice each session lasted approximately 40 minutes.

\subsection{Hypotheses}

As noted above, in the SPNE of the NE, WE and NoLM treatments, money-maximizing farmers will never trade, while in the SE treatment, they will always trade. Moreover, independent of treatment, money-maximizing traveling merchants will cheat in equilibrium. Experimental evidence from trust games, on the contrary, reveals extensive trust and reciprocity, inconsistent with pure money-maximizing behavior (Johnson and Mislin, 2011). We further hypothesize that individualistic and collectivistic tendencies may affect the willingness to engage in long-distance trade through two distinctive channels. 
To reiterate, individualists value their relationships instrumentally “[balancing] relationships' costs and benefits, leaving relationships and groups when the costs of participation exceed the benefits and creating new relationships as personal goals shift" (Oyserman et al., 2002, p. 5) while collectivists value their relationships intrinsically, implying "that (a) important group memberships are ascribed and fixed, viewed as 'facts of life' to which people must accommodate; (b) boundaries between in-groups and out-groups are stable, relatively impermeable, and important" (Oyserman et al., 2002, p. 5). In the context of this experiment, farmers may regard their history of trades with local merchants as merely a trade opportunity that was preferable to autarky (i.e. from an individualistic view) or as a personal relationship that also offered a trade opportunity (i.e. from a collectivistic view). In the narration, traveling merchants are portrayed as a potential better trade opportunity; however, trade with them imposes a negative externality on local merchants. Therefore, we have the following two hypotheses:

I/C Hypothesis 1a: Since collectivists value their relationships intrinsically, they will be less willing to engage in long-distance trade than individualists, due to the negative externality this imposes on local merchants in the NE, WE and SE treatments.

I/C Hypothesis 1b: In the NoLM treatment, which eliminates the negative externality of long-distance trade, this effect should disappear.

Another channel through which individualism and collectivism may affect long-distance trade is through differences in the way that traveling merchants' trade behavior influences farmers' beliefs. The pillar of collectivism is that individuals are interdependent. Hence, after being cheated once, collectivist farmers may expect all traveling merchants to be "cheaters" and may be deterred from future long-distance trade, despite the perfect stranger matching protocol used in the experiment. The pillar of individualism, on the other hand, "is the assumption that individuals are independent of one another" (Oyserman et al., 2002, p. 5, italics added). Thus when cheated, individualist farmers may not be deterred from future long-distance trade, since the action of one is not perceived as an indication of future actions by others. 
I/C Hypothesis 2: Since collectivists tend to focus on salient features of groups rather than individuals, their willingness to trade at time $t$ after being cheated at time $t-1$ will be lower than individualists, as collectivists are prone to assume the behavior of one traveling merchant is representative of the behavior of others.

\section{Experimental Results}

\subsection{I/C scores}

Using the Triad Task, we elicited I/C scores for each subject and used these to assign them to roles. In particular, we sampled all the people in the role of the farmer from the tails of the distribution. We have normalized the data so that a score of 0 means that a subject's responses to the triad task were $100 \%$ consistent with collectivism and a score of 1 means that the subject was $100 \%$ individualist. Figure 3 shows the overall distribution of I/C scores in the sample. As the distribution is clearly skewed towards collectivism, this supports our decision to sample from the tails in order to ensure that we have both individualistic and collectivistic subjects in the most important role. Finally, we note that there is no significant correlation between I/C scores and risk preference or gender (two-sided Spearman's rank correlation test $p$-values $=0.84$ and 0.41 , respectively, when we look at the entire sample, and $p$-values $=0.13$ and 0.52 , respectively, when we focus on subjects in the role of farmer). ${ }^{3}$

\subsection{The common stage}

The common stage was designed to induce a history between the farmers and local merchants. Hence, the decision for the farmers was a trivial one, either to keep their harvest and earn $A$ or trade with the local merchant and generate a payoff of $2 A$ for both parties with no risk of being cheated. The common stage also served as a test for both the clarity of the narrations and the

\footnotetext{
${ }^{3}$ Figure B1 in appendix B displays the distribution of choices in the risk preference elicitation for the curious reader.
} 


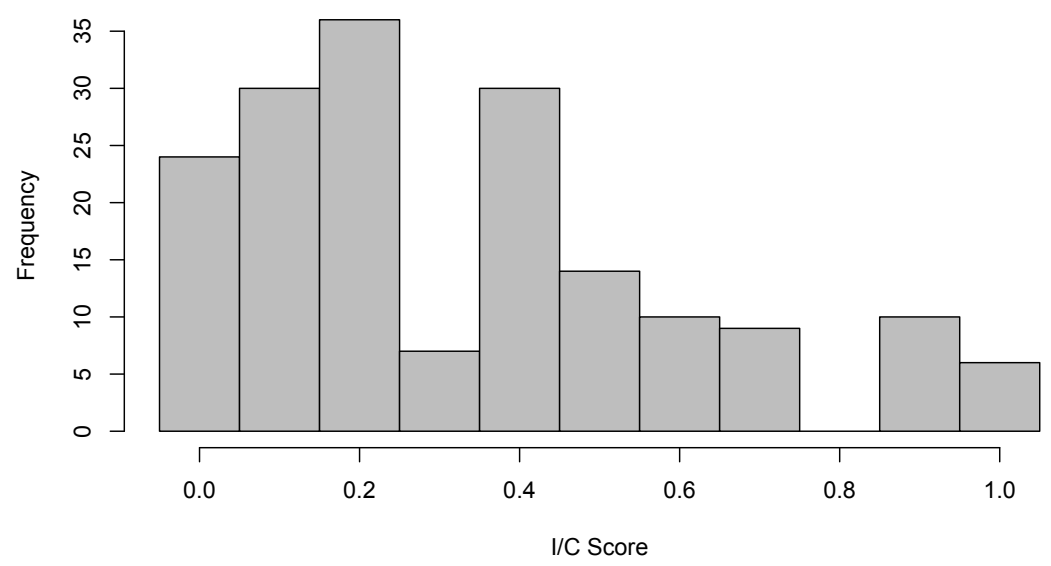

Figure 3: Histogram of I/C scores.

rationality of the farmers.

After twelve sessions, farmers collectively faced this decision 192 times and kept the harvest only three times. This shows that the gains from trading with the local merchant were salient to the farmers and that the farmers preferred more to less. As we will see below, this stage also appears to have succeeded in building a salient relationship between collectivistic farmers and the local merchant.

\subsection{The treatment stage}

Overall we observed 33 long-distance trades in the NE treatment, 32 trades in the WE treatment, and 42 trades in the SE treatment. Comparing at the session level, a Wilcoxon rank-sum test reveals no statistically significant difference in the amount of trade between the NE and WE treatments ( $p$-value $=1$, two-sided test). Pooling WE and NE which are predicted to be equivalent and compare them to SE, we find significantly more trade in SE, consistent with the comparative statics of the payoff-maximizing SPNE ( $p$-value $=0.05$, one-sided test).

Our main hypothesis pertains to the relationship between an individual's I/C score and her willingness to trade. ${ }^{4}$ Pooling the NE, WE and SE treatments, there is a positive and sig-

\footnotetext{
${ }^{4}$ Our hypotheses focus on farmers' behavior, and the I/C score distribution for traveling merchants is com-
} 
nificant correlation between the I/C score and the number of times that a subject engaged in long-distance trade (Spearman's $\rho=0.33, p$-value $=0.01$, one-sided test). Figure 4 shows the relationship between I/C score and willingness to trade, by treatment. Each line represents the predicted probability of trade in a single treatment and colored bands represent $90 \%$ confidence intervals from a logistic regression.

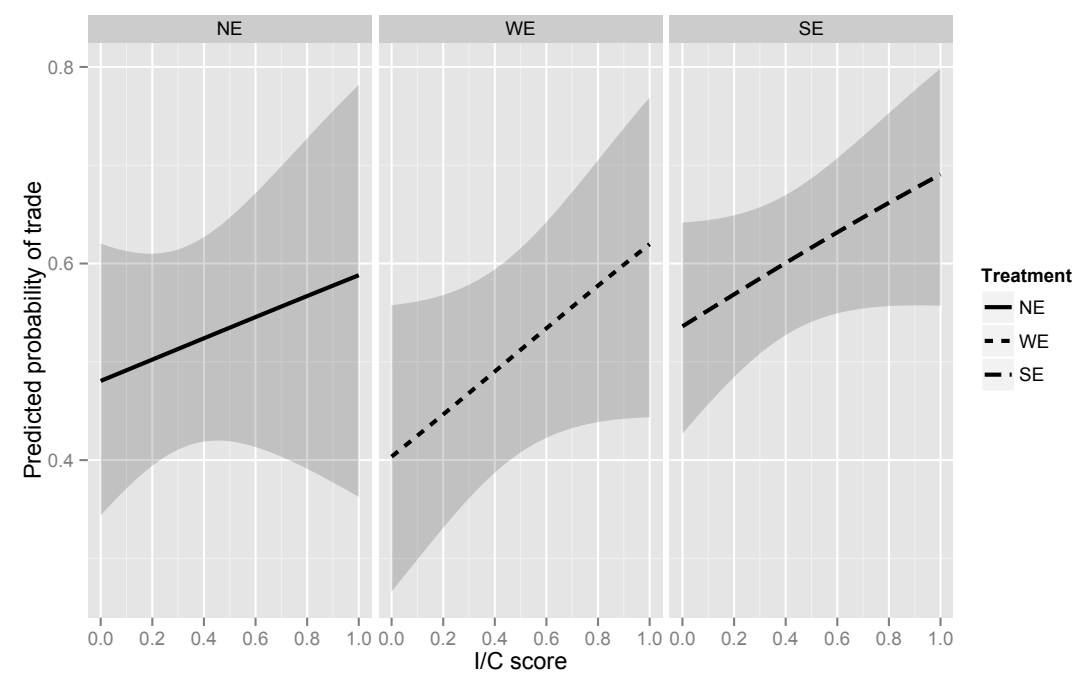

Figure 4: The relationship between I/C score and willingness to trade, by treatment. Each line represents the predicted probability of trade in a single treatment and colored bands represent $90 \%$ confidence intervals from a logistic regression.

To provide statistical support for an effect of individualist/collectivist culture on trade decisions, we estimate a panel regression model where the dependent variable is a dummy that takes a value of 1 if the farmer traded with the traveling merchant at time $t$ and 0 otherwise. The dependent variables include a constant term, the I/C score, and WE and SE treatment dummies. A second specification includes interactions between treatment and I/C score, and a third specification includes individual risk preferences, a female dummy, and risk times treatment interactions. In each specification, we include random effects for each subject to control for repeated observations and we cluster standard errors at the session level. The results are reported in columns (1)-(3) of Table 2.

pressed due to our role assignment algorithm. Thus we relegate analysis of traveling merchant decisions to appendix B. 
In all three specifications, once we control for I/C score the treatment effects are insignificant. Moreover, the more individualistic a farmer, the higher her probability of engaging in longdistance trade. ${ }^{5}$

Finding 1: Overall, individualists are more likely to trade than collectivists.

What drives these differences in behavior? If individualism encourages long-distance trade per se, as predicted by I/C Hypothesis 1a, then this difference should show up in the first period. In columns (4) and (5) of Table 2, we estimate the effect of I/C score and the treatments on first period trade using OLS and clustering standard errors at the session level. In column (4) we find no significant relationship between I/C score and trade but there is a significantly more trade in the first round of SE. When we include interactions, as in column (5), the main effect of the SE treatment is no longer significant. Moreover, Wald tests cannot reject the null hypotheses that the I/C score and I/C $\times$ treatment interactions sum to 0 ( $p$-values $>0.3)$, suggesting that there is no effect of the treatments in period 1.

Finding 2: In the first period of long-distance trade, there is no significant difference in the behavior of individualistic and collectivistic farmers, suggesting that if individualists and collectivists value the relationship with the local merchant differently, this effect is not strong enough to lead to differences in initial trade.

One possible confound is that there are initially systematic differences in the beliefs of individualists and collectivists about the probability that a traveling merchant will reciprocate (i.e. differences in trust). Thus, it is possible that collectivists value the relationship with the local merchant but also have more optimistic beliefs about the behavior of traveling merchants. Our NoLM treatment, which we discuss below, allows us to address this confound.

\footnotetext{
${ }^{5}$ Since e.g. risk-averse agents may still prefer not to trade in the SPNE of the SE treatment, and risk-lovers may prefer to trade, even in the WE treatment, we included the risk $\times$ treatment interactions. Lower values of the variable "risk" imply more risk-aversion. Wald tests indicate that there is no statistically significant effect of risk preferences in the NE, WE, or SE treatment, $p$-values $=0.70,0.11$, and 0.31 , respectively.
} 


\begin{tabular}{|c|c|c|c|c|c|c|c|}
\hline & $\begin{array}{c}(1) \\
\text { Trade }_{t}\end{array}$ & $\begin{array}{c}(2) \\
\text { Trade }_{t}\end{array}$ & $\begin{array}{c}(3) \\
\text { Trade }_{t}\end{array}$ & $\begin{array}{c}(4) \\
\text { Trade }_{1}\end{array}$ & $\begin{array}{c}(5) \\
\text { Trade }_{1}\end{array}$ & $\begin{array}{c}(6) \\
\text { Trade }_{t>1}\end{array}$ & $\begin{array}{c}(7) \\
\text { Trade }_{t>1}\end{array}$ \\
\hline I/C Score & $\begin{array}{c}0.234^{* *} \\
(0.098)\end{array}$ & $\begin{array}{c}0.108^{* *} \\
(0.046)\end{array}$ & $\begin{array}{l}0.105^{* *} \\
(0.051)\end{array}$ & $\begin{array}{c}0.096 \\
(0.153)\end{array}$ & $\begin{array}{l}-0.219 \\
(0.293)\end{array}$ & $\begin{array}{c}0.056 \\
(0.140)\end{array}$ & $\begin{array}{c}0.019 \\
(0.169)\end{array}$ \\
\hline Weak Enforcement & $\begin{array}{l}-0.044 \\
(0.089)\end{array}$ & $\begin{array}{l}-0.077 \\
(0.089)\end{array}$ & $\begin{array}{l}-0.384 \\
(0.268)\end{array}$ & $\begin{array}{l}-0.012 \\
(0.138)\end{array}$ & $\begin{array}{l}-0.146 \\
(0.209)\end{array}$ & $\begin{array}{l}-0.278 \\
(0.288)\end{array}$ & $\begin{array}{c}-0.380^{*} \\
(0.215)\end{array}$ \\
\hline Strong Enforcement & $\begin{array}{c}0.118 \\
(0.090)\end{array}$ & $\begin{array}{c}0.028 \\
(0.139)\end{array}$ & $\begin{array}{l}-0.088 \\
(0.293)\end{array}$ & $\begin{array}{c}0.241^{* *} \\
(0.095)\end{array}$ & $\begin{array}{c}0.069 \\
(0.179)\end{array}$ & $\begin{array}{l}-0.128 \\
(0.346)\end{array}$ & $\begin{array}{l}-0.267 \\
(0.302)\end{array}$ \\
\hline $\mathrm{WE} \times \mathrm{I} / \mathrm{C}$ & & $\begin{array}{c}0.109 \\
(0.116)\end{array}$ & $\begin{array}{c}0.060 \\
(0.081)\end{array}$ & & $\begin{array}{c}0.388 \\
(0.362)\end{array}$ & $\begin{array}{c}0.017 \\
(0.139)\end{array}$ & $\begin{array}{c}0.030 \\
(0.198)\end{array}$ \\
\hline $\mathrm{SE} \times \mathrm{I} / \mathrm{C}$ & & $\begin{array}{c}0.241 \\
(0.231)\end{array}$ & $\begin{array}{c}0.247 \\
(0.277)\end{array}$ & & $\begin{array}{c}0.480 \\
(0.380)\end{array}$ & $\begin{array}{c}0.164 \\
(0.323)\end{array}$ & $\begin{array}{c}0.298 \\
(0.348)\end{array}$ \\
\hline Risk & & & $\begin{array}{c}0.011 \\
(0.028)\end{array}$ & & & $\begin{array}{c}0.030 \\
(0.048)\end{array}$ & $\begin{array}{c}0.025 \\
(0.046)\end{array}$ \\
\hline WE $\times$ Risk & & & $\begin{array}{c}0.070 \\
(0.067)\end{array}$ & & & $\begin{array}{c}0.038 \\
(0.071)\end{array}$ & $\begin{array}{c}0.038 \\
(0.062)\end{array}$ \\
\hline $\mathrm{SE} \times$ Risk & & & $\begin{array}{c}0.024 \\
(0.047)\end{array}$ & & & $\begin{array}{c}0.028 \\
(0.062)\end{array}$ & $\begin{array}{c}0.022 \\
(0.055)\end{array}$ \\
\hline Female & & & $\begin{array}{c}0.011 \\
(0.096)\end{array}$ & & & $\begin{array}{c}0.026 \\
(0.089)\end{array}$ & $\begin{array}{c}0.024 \\
(0.080)\end{array}$ \\
\hline Cheat $_{t-1}$ & & & & & & $\begin{array}{c}-0.249^{*} \\
(0.138)\end{array}$ & $\begin{array}{c}-0.595^{* * *} \\
(0.111)\end{array}$ \\
\hline Cheat $_{t-1} \times \mathrm{I} / \mathrm{C}$ & & & & & & $\begin{array}{c}0.519^{* * *} \\
(0.161)\end{array}$ & $\begin{array}{c}0.698^{* *} \\
(0.323)\end{array}$ \\
\hline Cheat $_{t-1} \times \mathrm{WE}$ & & & & & & & $\begin{array}{c}0.559^{* *} \\
(0.260)\end{array}$ \\
\hline Cheat $_{t-1} \times \mathrm{SE}$ & & & & & & & $\begin{array}{c}0.708^{* * *} \\
(0.165)\end{array}$ \\
\hline Cheat $_{t-1} \times \mathrm{I} / \mathrm{C} \times \mathrm{WE}$ & & & & & & & $\begin{array}{l}-0.273 \\
(0.468)\end{array}$ \\
\hline Cheat $_{t-1} \times \mathrm{I} / \mathrm{C} \times \mathrm{SE}$ & & & & & & & $\begin{array}{l}-0.545 \\
(0.397)\end{array}$ \\
\hline Intercept & $\begin{array}{c}0.440^{* * *} \\
(0.076)\end{array}$ & $\begin{array}{c}0.481^{* * *} \\
(0.065)\end{array}$ & $\begin{array}{c}0.439^{* * *} \\
(0.113)\end{array}$ & $\begin{array}{c}0.469^{* * *} \\
(0.110)\end{array}$ & $\begin{array}{c}0.571^{* * *} \\
(0.145)\end{array}$ & $\begin{array}{c}0.403^{* * *} \\
(0.123)\end{array}$ & $\begin{array}{c}0.499^{* * *} \\
(0.113)\end{array}$ \\
\hline Observations & 192 & 192 & 192 & 48 & 48 & 144 & 144 \\
\hline $\mathrm{R}^{2}$ & 0.05 & 0.06 & 0.09 & 0.06 & 0.09 & 0.10 & 0.19 \\
\hline
\end{tabular}

Clustered standard errors in parentheses. ${ }^{*} \mathrm{p}<0.1,{ }^{* *} \mathrm{p}<0.05,{ }^{* * *} \mathrm{p}<0.01$.

Table 2: Regression Analysis of the Decision to Trade

Given that we find no per se differences in trade behavior in the first round, we examine the second potential source of correlation between trade and I/C score. According to I/C Hypothesis 2, differences between the types develop dynamically through their histories of interaction with traveling merchants. In particular, when trading, both types may be cheated, but the effect 
of being cheated on their subsequent willingness to trade may vary across types. To test for these dynamic effects, we estimate two additional regression specifications in which we include a dummy variable that takes a value of 1 when a farmer was cheated in the previous period and 0 otherwise. In column (6), we estimate the same model as in column (3) and add this variable and an I/C $\times$ Cheat $_{t-1}$ interaction; while, in column (7) we also include interactions between the lagged cheating variable, the I/C score, and the treatments.

In column (6), the overall effect of cheating is negative and significant, while the interaction with I/C score is positive and significant. This indicates a heterogeneous reaction to being cheated by individualists and collectivists. Specifically, when cheated, collectivists are less likely to trade in the future, while individualists remain just as likely, or more so, to trade. In column (7), we find positive and significant interactions between Cheat ${ }_{t-1}$ and the WE and SE treatments, suggesting that the presence of exogenous enforcement dampens the negative impact on trade of having been cheated the past in those treatments. The triple interactions with I/C are insignificant, and the overall higher likelihood of trading for individualists, conditional on having been cheated, remains (i.e. we see a positive and significant coefficient on the I/C $\times \mathrm{Cheat}_{t-1}$ interaction).

Figure 5 summarizes these findings graphically. The figure reveals that, when cheated, collectivists substantially reduce their future willingness to trade, while individualists, on the whole, do not. In keeping with our opening quote, this evidence suggests that individualists treat traveling merchants in isolation, as if their behavior is independent of one another, while collectivists appear to assign blame to the entire set of traveling merchants for the misbehavior of one.

Finding 3: Consistent with I/C Hypothesis 2, individualists and collectivists react differently to being cheated when engaging in long-distance trade. Individualists are less deterred from future trade than collectivists.

In the NE treatment the negative effect of being cheated is at its peak to the point that collectivists almost completely opt out of long-distance trade after being cheated. However, interestingly, both the negative coefficients on the triple-interaction terms (Cheat $t_{t-1} \times \mathrm{I} / \mathrm{C} \times$ Treatment) $^{-1}$ 


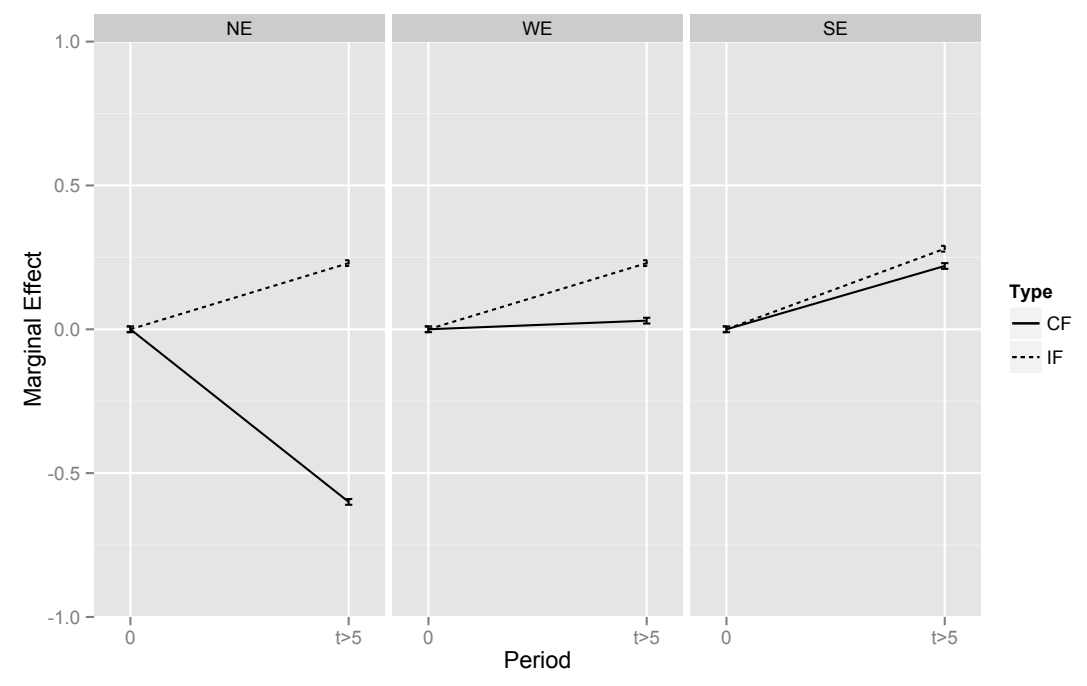

Figure 5: The marginal effect of cheating on trade, by treatment and I/C score. Each panel plots the data for one treatment. The left side shows the origin. The right side shows the marginal effect on trade probability of having been cheated in the previous period for each type in periods 6-8. Using column (7) of table 2, we compute the marginal effect from a logistic regression at the upper and lower quartiles of the farmers' I/C score distribution for individualists (IF) and collectivists $(\mathrm{CF})$, respectively.

in column (7) of table 2 and the marginal effects depicted in figure 5 suggest that the court system mitigates this effect. This is consistent with the historical evidence from Greif (2000), in which the role of the formal enforcement is to mitigate the "fundamental problem of exchange." 6

Finding 4: A strong court system mitigates the effects of cultural dispositions.

\subsection{Robustness}

\subsubsection{No Local Merchant}

To better understand the source of our findings, we ran the NoLM treatment in which there was no human local merchant who was harmed by the decision of a farmer to trade with a

\footnotetext{
${ }^{6}$ Although, in this experiment, an exogenously implemented court system mitigates the effects of culture, in practice institutions are rarely exogenously imposed. In a recent experiment which compares the endogenous institutional choices of individualists and collectivists, Hajikhameneh (Working paper) found that collectivists are inclined to employ an informal reputation system to enforce long-distance trade when both a reputation system and a court system are simultaneously available. This suggests that cultural dispositions also influence preferences over institutions, which may help explain why some cultures are less likely to develop and employ formal enforcement institutions, despite their apparent effectiveness.
} 
traveling merchant. We retained the framing of the game as the decision to trade in a local or foreign market, and we retained the initial 4 periods in which the farmer makes a trivial decision between autarky $(A)$ and local "trade" $(2 A)$. In each of periods 5-8, a new traveling merchant appeared just as before, and the pair played a standard, extensive form trust game, with no court (i.e. $\gamma, C=0$ ).

This treatment helps illuminate two aspects of the data and provides a manipulation check on an important feature of our experimental design. First, it allows us to address the concern that the initial lack of differences between types in the NE, WE, and SE treatments is driven by offsetting effects of different beliefs and different values of the relationship with the local merchant. In NoLM, there is no human local merchant, so different beliefs, if they exist, should now lead to different trade behavior. Second, there is the possibility that the two mechanisms interact, which was not captured in our initial hypotheses. If collectivists revert to local trade after being cheated due, in part, to their higher value for the relationship with the local merchant, then removing this local merchant should reduce the dynamic differences between types. Finally, if observed behavior changes in the NoLM treatment, this provides evidence that our narrativized game in the NE treatment successfully induces the perception of a personal relationship between the farmer and the local merchant, by contrast to the impersonal relationship(s) with the traveling merchant(s).

We conducted 4 sessions of the NoLM treatment. ${ }^{7}$ In each session 8 subjects participated, for a total of 32 subjects. After subjects completed the Triad Task, we assigned the two most collectivistic and the two most individualistic subjects as the farmers. The remaining subjects were assigned the role of traveling merchants. Following the role assignment, subjects, first, play the common stage for 4 periods and then 4 periods of the NoLM treatment. During the common stage and the NoLM treatment subjects earned ECU which is converted to CAD at a rate $12 \mathrm{ECU}=1 \$$. Similar to the NE, WE, and $\mathrm{SE}$ treatments, subjects' earnings from all the 8 periods and the risk-preference elicitation task were summed and paid to them at end of each

\footnotetext{
${ }^{7}$ Experiments were conducted at Simon Fraser University in June 2015.
} 
session. The payment range was from $12 \mathrm{CAD}$ to $21 \mathrm{CAD}$ including a 7CAD show-up fee. We recruited subjects for 1 hour sessions. However, on average, each session lasted approximately 40 minutes.

\begin{tabular}{|c|c|c|}
\hline & $\begin{array}{c}(1) \\
\text { Trade }_{1}\end{array}$ & $\begin{array}{c}(2) \\
\text { Trade }_{t}\end{array}$ \\
\hline I/C Score & $\begin{array}{l}-0.219 \\
(0.299)\end{array}$ & $\begin{array}{c}0.026 \\
(0.175)\end{array}$ \\
\hline NoLM & $\begin{array}{l}-0.040 \\
(0.235)\end{array}$ & $\begin{array}{l}-0.428 \\
(0.342)\end{array}$ \\
\hline I/C Score $\times$ NoLM & $\begin{array}{c}0.144 \\
(0.315)\end{array}$ & $\begin{array}{l}-0.019 \\
(0.331)\end{array}$ \\
\hline Risk & & $\begin{array}{c}0.011 \\
(0.050)\end{array}$ \\
\hline NoLM $\times$ Risk & & $\begin{array}{l}0.108^{*} \\
(0.065)\end{array}$ \\
\hline Female & & $\begin{array}{l}-0.057 \\
(0.176)\end{array}$ \\
\hline Cheat $_{t-1}$ & & $\begin{array}{c}-0.596^{* * *} \\
(0.117)\end{array}$ \\
\hline I/C Score $\times$ Cheat $_{t-1}$ & & $\begin{array}{l}0.593^{* *} \\
(0.295)\end{array}$ \\
\hline NoLM $\times$ Cheat $_{t-1}$ & & $\begin{array}{c}0.463 \\
(0.367)\end{array}$ \\
\hline I/C Score $\times$ NoLM $\times$ Cheat $_{t-1}$ & & $\begin{array}{l}-0.745 \\
(0.456)\end{array}$ \\
\hline Intercept & $\begin{array}{c}0.571^{* * *} \\
(0.147)\end{array}$ & $\begin{array}{c}0.589^{* * *} \\
(0.204)\end{array}$ \\
\hline $\begin{array}{l}\text { Observations } \\
\mathrm{R}^{2}\end{array}$ & $\begin{array}{c}32 \\
0.01\end{array}$ & $\begin{array}{c}96 \\
0.19\end{array}$ \\
\hline
\end{tabular}

Table 3: Regression Analysis of the Decision to Trade After Being Cheated, NE and NoLM

Overall, in NoLM we observe 35 instances of trade, and there is no significant difference in trade at the session level between the NoLM and NE treatments (two-sided Wilcoxon test, $p$ value $=0.88)$. Moreover, within the NoLM treatment we find no significant correlation between $\mathrm{I} / \mathrm{C}$ score and the number of times a subject traded with the foreign merchant (Spearman's $\rho=$ $-0.09, p$-value $=0.75)$. To test whether eliminating the human local merchant influences initial propensity to trade, we estimate the effect of I/C score and the treatments on trade in period 1 
using OLS and clustering standard errors at the session level. To compare the dynamic effect of cheating in the NE and NoLM treatment, we estimate a panel GLS model in which the dependent variable takes a value of 1 if the farmer traded and a value of 0 otherwise. The independent variables include, an Intercept, the I/C score, a NoLM dummy, individual risk preferences, a female dummy, a risk times treatment interaction, a dummy that takes a value of 1 when the farmer was cheated in the previous period and 0 otherwise, and all possible interactions between I/C, NoLM and lagged cheating. We include random effects for each subject to control for repeated observations and we cluster standard errors at the session level.

Regression output is reported in Table 3. In column (1), we find no evidence of initial differences in the willingness to trade across types suggesting that differences in initial beliefs cannot explain our observations above. In column (2), as before, we find a negative and significant overall effect of being cheated in the previous period on current period trade. Moreover, this is offset among individualists in the NE treatment, and a Wald test cannot reject the null hypothesis that the coefficients on lagged cheating and the Cheat $_{t-1} \times \mathrm{I} / \mathrm{C}$ Score interaction sum to $0(p$-value $=$ 0.99). However, the three-way interaction of Cheat $_{t-1} \times \mathrm{I} / \mathrm{C}$ Score $\times$ NoLM is large and negative. Alone it is not statistically significant, but a Wald test cannot reject the null that the sum of the Cheat $t_{t-1} \times \mathrm{I} / \mathrm{C}$ Score interaction and the three-way interaction is equal to 0 ( $p$-value $=0.67$ ). Taken together, this provides evidence that the dynamic effects of cheating on individualists and collectivists are not statistically distinguishable in the NoLM treatment.

Figure 6 summarizes these observations graphically. The figure reveals no substantial behavioral differences between the types in the NoLM treatment. Finally, a positive and marginally significant coefficient on the Risk $\times$ NoLM variable indicates that subjects who are willing to take more risk trade more often in the NoLM treatment, which provides some evidence that beliefs drive decision-making in the NoLM treatment. Risk was insignificant in every other treatment.

Finding 5: In the NoLM treatment, there are no substantial behavioral differences between individualist and collectivist farmers.

Thus far, we have established that individualists are more likely to trade than collectivists in 


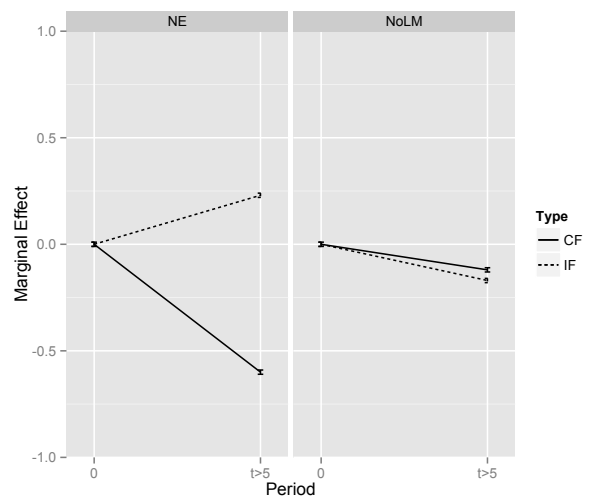

Figure 6: The marginal effect of cheating on trade in the NoLM treatment, by I/C score. The left side shows the origin. The right side shows the marginal effect on the probability of trade of having been cheated in the previous period for each type in periods 6-8. Using column (2) of table 3, we compute the marginal effect from a logistic regression at the upper and lower quartiles of the farmers' I/C score distribution for individualists (IF) and collectivists (CF), respectively.

the NE, WE, and SE treatments and that in the absence of human local merchants, in the NoLM treatment, we observe no significant behavioral differences between individualists and collectivists. However, the channel through which individualism encouraged long-distance trade is still ambiguous. To clarify what aspects of individualism are conducive to long-distance trade we run two additional incentivized tasks.

\subsubsection{Norm Elicitation and Belief Elicitation}

Do subjects high on the individualism spectrum believe that long-distance trade, regardless of the negative externality imposed on local merchants, is more normatively appealing as compared to their collectivist counterparts? Are individualists more optimistic regarding traveling merchants' cooperation than collectivists? In an attempt to describe the underlying mechanisms which shape trade behavior, and to further probe the heterogeneity of social norms and beliefs across the individualism/collectivism spectrum, we ran incentivized norm and belief elicitation tasks (Krupka and Weber, 2013; Kimbrough and Vostroknutov, 2016; Karni, 2009).

To provide answers to the aforementioned questions, we elicit normative and strategic beliefs about trade behavior in two separate tasks. In task 1, the "norm elicitation" task, we elicit beliefs about social norms. That is, we measure the social appropriateness of each one of the farmers' 
available actions. According to Greif (1994) cultural/social norms are "the ideas and thoughts common to several individuals that govern interaction between [them]" (p.915). Hence, in the context of this experiment, individualists and collectivists may have different injunctive social norms about the appropriateness of farmers' actions. For instance, collectivists may think it is more wrong to abandon trade with the local merchant.

To reiterate, in each round of treatment, farmers have the following three options: "keep the harvest", "trade with the local merchant", and "trade with the traveling merchant". Subjects, in the norm elicitation task, read the farmer's narration ${ }^{8}$ and had to evaluate each action on a fourpoint scale (that is, "very inappropriate", " somewhat inappropriate", " somewhat appropriate", and "very appropriate") with the simple instruction that they would get paid $\$ 8$ only if their answers correspond to the most frequent response given by other subjects in the lab. Otherwise, they would get $\$ 0$. This payment method captures the idea of injunctive social norms as it incentivizes subjects to reveal their beliefs about what others believe is socially appropriate (what ought to be done). For this task's payment, one of the three questions was randomly drawn by the computer and subjects were paid accordingly.

Furthermore, in task 2, the belief elicitation task, we elicit beliefs of the likelihood of reciprocation by traveling merchants. Subjects, after reading the traveling merchants' narration, ${ }^{9}$ had to decide "what is the probability that the traveling merchant shares the profit?" We employ a random reward lottery method such that it is optimal under weak conditions for subjects to report truthfully (Karni, 2009). That is, this method is truth revealing as long as subjects have monotonic preferences over money, are probabilistically sophisticated (such that they make their choice based only on the "implied probability distribution over outcomes") and have no ulterior stake in any particular outcome (Karni, 2009, p.604).

We had a total of 29 subjects complete the norm and belief elicitation tasks in sequence. For

\footnotetext{
${ }^{8}$ Subjects, from the farmers' point of view, see the common stage narration. They are informed that this stage lasted for four periods in the sessions conducted in the same laboratory a year ago. Next, subjects read the NE treatment narration. For details, see appendix A.2.

${ }^{9}$ Subjects see the same sequence of the narration as a traveling merchant would in the NE treatment. For details, see appendix A.2.
} 
the final payment, one of the appropriateness or probability task was randomly chosen with equal probability. The average payment was 12.54CAD including a 7CAD show up fee. Figure 7 reports the histogram of the distribution of the I/C score in the norm elicitation task. The horizontal axis represents the normalized I/C score in which 0 represents the maximum collectivism while 1 represents the maximum individualism.

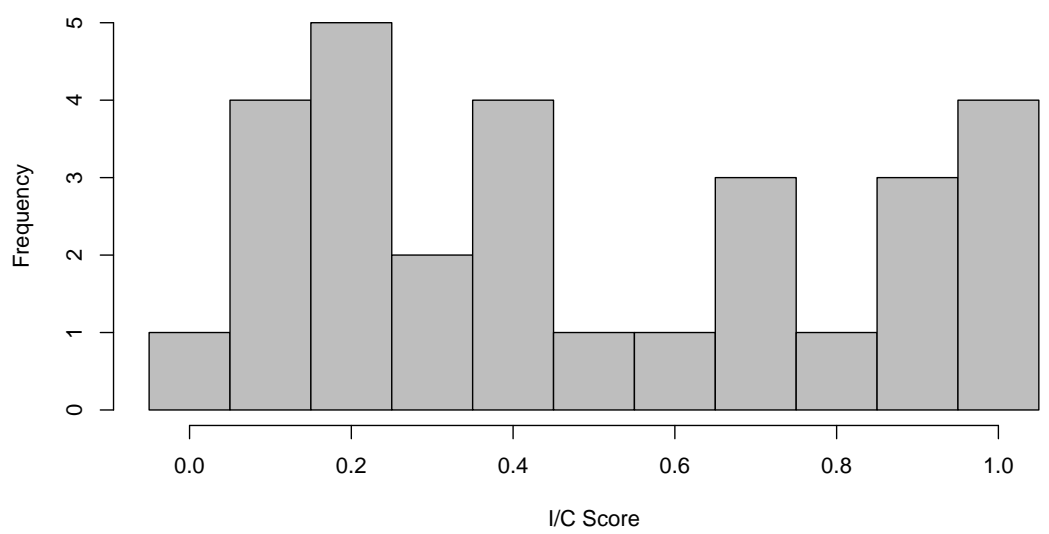

Figure 7: Histogram of I/C scores in the norm and belief elicitation tasks.

We observe no significant correlation between the perceived social appropriateness of farmers' actions and I/C score. This may suggest that individualists are not socially less sensitive to their local merchants' plight compared to collectivists. ${ }^{10}$ The result of the belief elicitation task, however, indicates that individualists are significantly more optimistic regarding the probability of traveling merchants' reciprocation (Spearman's $\rho=0.41, p-$ value $=0.03$ ).

Finding 6: Overall, individualists perceive traveling merchants to be more cooperative than collectivists.

\footnotetext{
${ }^{10}$ However, since subjects are paid based on whether their response corresponds to that of others in the room, this task may not incentivize them to reveal their own normative beliefs if they think others have different views. That is, unfortunately, we may observe only the overall average of normative beliefs and not how such beliefs vary with dispositions to individualism or collectivism.
} 


\section{Discussion and Conclusion}

In this paper, using a laboratory experiment, we examined how individualism and collectivism affect the propensity to engage in impersonal, long-distance trade under formal enforcement mechanisms of varying strength. Our findings suggest that individualists tend to be more willing to trade than collectivists. Two channels through which collectivism dampens long-distance trade are the external cost imposed on local merchants and the stereotyping of traveling merchants. In particular, we find that individualist farmers are less deterred from trade by cheating than are collectivist farmers. Stronger formal enforcement, however, mitigates this difference. This suggests that institutions and culture may be substitutes in the promotion of trade and that 'getting the institutions right' could have a powerful impact on prospects for trade. ${ }^{11}$

In our experiment, the externality on the local merchant is not strong enough to cause a significant behavioral difference in the first period of any treatment; however, upon eliminating the role of local merchant in the NoLM treatment, the differential response to being cheated observed in the NE, WE, and SE treatments, disappears. This indicates the importance of social context to the collectivist farmers, as their decisions are responsive to externalities imposed on their local merchant counterparts. The norm and belief elicitation tasks also established that individualists perceive traveling merchants to be more cooperative than collectivists. Our findings suggest that cultural dispositions have clear economic consequences by influencing individuals' decision-making process and therefore the probability of engaging in long-distance trade.

Finally, until now, most studies of collectivism and individualism have employed field experiments (Talhelm et al., 2014; Leibbrandt et al., 2013). We believe that this experiment provided a useful tool to bring the study of the effect cultural dispositions on economic variables into the laboratory setting, and we believe that this will encourage future research exploring the connections between culture and behavior in the lab.

\footnotetext{
${ }^{11}$ However, this overlooks that fact that institutions are typically endogenous to culture. Taking this into account, Hajikhameneh (Working paper) shows that the triad task also helps predict the choice of formal vs. informal institutions for trade. Thus while institutions may substitute for culture, cultural factors may prevent efficiency enhancing institutions from being adopted in the first place.
} 


\section{References}

BERG, J., DiCKHAUT, J. and MCCABE, K. (1995). Trust, reciprocity, and social history. Games and Economic Behavior, 10 (1), 122-142.

Bernhard, H., Fischbacher, U. and FeHR, E. (2006). Parochial altruism in humans. Nature, 442 (7105), 912-915.

BOHNET, I., FREY, B. S. and HUCK, S. (2001). More order with less law: On contract enforcement, trust, and crowding. American Political Science Review, 95 (1), 131-144.

-, Greig, F., Herrmann, B. and Zeckhauser, R. (2008). Betrayal aversion: Evidence from brazil, china, oman, switzerland, turkey, and the united states. American Economic Review, pp. 294-310.

-, HARMgART, H., TYRAN, J.-R. et al. (2005). Learning trust. Journal of the European Economic Association, 3 (2-3), 322-329.

- and HUCK, S. (2004). Repetition and reputation: Implications for trust and trustworthiness when institutions change. American Economic Review, 94 (2), 362-366.

Briley, D. A., MORRIS, M. W. and SimOnSON, I. (2000). Reasons as carriers of culture: Dynamic versus dispositional models of cultural influence on decision making. Journal of consumer research, 27 (2), 157-178.

CAssar, A., Friedman, D. and Schneider, P. H. (2010). A laboratory investigation of networked markets. The Economic Journal, 120 (547), 919-943.

Charness, G., DU, N. and YANG, C.-L. (2011). Trust and trustworthiness reputations in an investment game. Games and Economic Behavior, 72 (2), 361-375.

CHIU, L.-H. (1972). A cross-cultural comparison of cognitive styles in chinese and american children. International journal of psychology, 7 (4), 235-242.

Cox, J. C. (2004). How to identify trust and reciprocity. Games and Economic Behavior, 46 (2), 260 -281 .

— and DECK, C. A. (2005). On the nature of reciprocal motives. Economic Inquiry, 43 (3), $623-635$.

ECKEL, C. C. and WILSON, R. K. (2004). Is trust a risky decision? Journal of Economic Behavior E Organization, 55 (4), 447-465.

FEHR, E. (2009). On the economics and biology of trust. Journal of the European Economic Association, 7 (2-3), 235-266.

- and FISCHBACHER, U. (2004). Third-party punishment and social norms. Evolution and Human Behavior, 25 (2), 63-87.

— and LIST, J. A. (2004). The hidden costs and returns of incentives-trust and trustworthiness among ceos. Journal of the European Economic Association, 2 (5), 743-771. 
- and Rockenbach, B. (2003). Detrimental effects of sanctions on human altruism. Nature, 422 (6928), 137-140.

FISCHBACHER, U. (2007). z-tree: Zurich toolbox for ready-made economic experiments. Experimental Economics, 10 (2), 171-178.

Green, E. G., Deschamps, J.-C. and PAeZ, D. (2005). Variation of individualism and collectivism within and between 20 countries a typological analysis. Journal of Cross-Cultural Psychology, 36 (3), 321-339.

GREIF, A. (1994). Cultural beliefs and the organization of society: A historical and theoretical reflection on collectivist and individualist societies. Journal of political economy, pp. 912-950.

- (2000). The fundamental problem of exchange: a research agenda in historical institutional analysis. European Review of Economic History, 4 (03), 251-284.

HAJIKHAMENEH, A. (Working paper). Individualism, collectivism, and alternative enforcement mechanisms in exchange.

HAKIM, N., SimONS, D. J., ZHAO, H. and WAN, X. (2016). Do easterners and westerners differ in visual cognition? a preregistered examination of three visual cognition tasks. Social Psychological and Personality Science, p. 1948550616667613.

HEALY, P. J. (2007). Group reputations, stereotypes, and cooperation in a repeated labor market. American Economic Review, 97 (5), 1751-1773.

HENRICH, J. (2014). Rice, psychology, and innovation. Science, 344 (6184), 593-594.

Hofstede, G. (1980). Culture's consequences. Beverly Hills: Sage.

Holt, C. and LAUry, S. (2002). Risk aversion and incentive effects. American Economic Review, 92 (5), 1644-1655.

Houser, D., SCHUNK, D. and WINTER, J. (2010). Distinguishing trust from risk: an anatomy of the investment game. Journal of Economic Behavior \& Organization, 74 (1), 72-81.

HUCK, S. and LÜNSER, G. K. (2010). Group reputations: An experimental foray. Journal of Economic Behavior \& Organization, 73 (2), 153 - 157.

HUI, C. H. and TRIANDIS, H. C. (1986). Individualism-collectivism a study of cross-cultural researchers. Journal of Cross-Cultural Psychology, 17 (2), 225-248.

Ji, L.-J., ZHANG, Z. and NiSBETT, R. E. (2004). Is it culture or is it language? examination of language effects in cross-cultural research on categorization. Journal of personality and social psychology, 87 (1), 57.

Johnson, N. D. and Mislin, A. A. (2011). Trust games: A meta-analysis. Journal of Economic Psychology, 32 (5), 865-889. 
KARLAN, D. S. (2005). Using experimental economics to measure social capital and predict financial decisions. American Economic Review, pp. 1688-1699.

KARNI, E. (2009). A mechanism for eliciting probabilities. Econometrica, 77 (2), 603-606.

Kimbrough, E. O. and RuBIN, J. (2015). Sustaining group reputation. Journal of Law, Economics, and Organization, 31 (3), 599-628.

- and Vostroknutov, A. (2016). Norms make preferences social. Journal of the European Economic Association, 14 (3).

Kitayama, S., Duffy, S., KaWAmura, T. and LARSEn, J. T. (2003). Perceiving an object and its context in different cultures a cultural look at new look. Psychological Science, 14 (3), 201-206.

-, PArk, H., Sevincer, A. T., KarasawA, M. and Uskul, A. K. (2009). A cultural task analysis of implicit independence: comparing north america, western europe, and east asia. Journal of personality and social psychology, 97 (2), 236.

Kreps, D. M., Milgrom, P., Roberts, J. and Wilson, R. (1982). Rational cooperation in the finitely repeated prisoners' dilemma. Journal of Economic Theory, 27 (2), 245-252.

KRUPKA, E. L. and WEBER, R. A. (2013). Identifying social norms using coordination games: Why does dictator game sharing vary? Journal of the European Economic Association, 11 (3), 495-524.

KURAN, T. (2010). Institutional causes of economic underdevelopment in the middle east: a historical perspective. Research of Institutional Economics, 3, 16.

LEIBbrandT, A., GNEEZY, U. and List, J. A. (2013). Rise and fall of competitiveness in individualistic and collectivistic societies. Proceedings of the National Academy of Sciences, 110 (23), 9305-9308.

McCABe, K. A., Rigdon, M. L. and Smith, V. L. (2003). Positive reciprocity and intentions in trust games. Journal of Economic Behavior and Organization, 52 (2), 267-275.

Nisbett, R. E., Peng, K., Choi, I. and Norenzayan, A. (2001). Culture and systems of thought: holistic versus analytic cognition. Psychological review, 108 (2), 291.

NORTH, D. C. (1990). Institutions, Institutional Change and Economic Performance. Cambridge University Press.

Osborn, J., Wilson, B. J. and SHerWOOD, B. R. (2015). Conduct in narrativized trust games. Southern Economic Journal, 81 (3), 562-597.

Oyserman, D., CoOn, H. M. and Kemmelmeier, M. (2002). Rethinking individualism and collectivism: Evaluation of theoretical assumptions and meta-analyses. Psychological Bulletin, $128(1), 3-72$.

R DeVElopment CORE TEAM (2012). R: A Language and Environment for Statistical Computing. R Foundation for Statistical Computing, Vienna, Austria, ISBN 3-900051-07-0. 
SCHeCHTER, L. A. (2005). Trust, trustworthiness, and risk in rural Paraguay. Ph.D. thesis, Citeseer.

SCHWARTZ, S. H. (1992). Universals in the content and structure of values: Theoretical advances and empirical tests in 20 countries. Advances in experimental social psychology, 25, 1-65.

SMith, V. L. and WILSON, B. J. (forthcoming). Sentiments, conduct, and trust in the laboratory. Social Philosophy and Policy.

Talhelm, T., Haidt, J., Oishi, S., Zhang, X., MiaO, F. F. and Chen, S. (2015). Liberals think more analytically (more "weird") than conservatives. Personality and Social Psychology Bulletin, 41 (2), 250-267.

-, ZhanG, X., Oishi, S., Shimin, C., DuAn, D., LAN, X. and KitAYAMA, S. (2014). Large-scale psychological differences within china explained by rice versus wheat agriculture. Science, 344 (6184), 603-608.

TRIANDIS, H. C. (1995). Individualism \& Collectivism. Westview Press.

— (2001). Individualism-collectivism and personality. Journal of Personality, 69 (6), 907-924.

-, Bontempo, R., Villareal, M. J., Asai, M. and LucCA, N. (1988). Individualism and collectivism: Cross-cultural perspectives on self-ingroup relationships. Journal of personality and Social Psychology, 54 (2), 323.

-, McCusker, C. and Hui, C. H. (1990). Multimethod probes of individualism and collectivism. Journal of personality and social psychology, 59 (5), 1006. 


\section{Appendices}

\section{A Experiment Instructions}

This part presents what subjects see on their screens during the experiment. Information would be given to the subjects in the sequential manner based on their decisions. Subjects will assume their roles (i.e. farmer, local merchant, or traveling merchant) in the beginning of the experiment according to the triad task results. The only difference between WE and SE treatments is the court enforcement power. Therefore, here we only give the WE narration.

\section{A.1 The Narrations}

\section{A.1.1 The common stage}

Farmers' narration (period 1) You are a farmer in a small county. You have to work hard around the clock to harvest your products. You can do two things with your harvest. First, you can give your harvest to a local merchant who sells some of it for you. This is a long-standing relationship, and each time you deal with the local merchant, both of you make 8ECU.

Second, you can keep your harvest and try to sell everything yourself. In this case both you and the local merchant payoff are equal to $4 \mathrm{ECU}$.

You can either keep your harvest or let a local merchant sell it in the local market.

$$
\text { Keep your harvest Trade with local merchant }
$$

Local merchants' narration (period 1) You are a merchant who sells goods in a local market. You have a long-standing relationship with a farmer who often gives you his harvest to sell at the market. When the farmer gives you the harvest, each of you gets 8ECU.

If farmer decides to not deal with you then you have to live off of your garden and both of you get 4ECU.

$$
\text { Ready to go on }
$$

Travelling merchants' narration (period 1) You are a travelling merchant accustomed to dealing with different people and markets. To make your living selling merchandise, you have to travel all year long. Farmers work hard around the clock to collect their harvest. If you travel to a village and find a farmer who is willing to trade you his harvest, you both can possibly gain from trade. But if you do not find a farmer or if the farmer is unwilling to trade with you, then you will have no opportunity to trade. Your payoff will be $4 \mathrm{ECU}$.

$$
\text { Ready to go on }
$$

Traveling merchants' narration (Period 2 to 4) You traveled this period but you were unsuccessful in finding a farmer to trade with.

$$
\text { Ready to go on }
$$

Farmers' narration (periods 2 to 4) You have two options. Keeping your harvest for yourself, this pays you 4ECU, or giving your products to a local merchant who sells them and pays you 8ECU.

$$
\text { Keep your harvest Trade with local merchant }
$$




\section{A.1.2 The NE treatment}

Farmers' narration (periods 5) A travelling merchant has arrived in your county. Travelling merchants know different people and foreign markets. They travel all year long selling merchandise to the highest bidder. This merchant has offered to take your harvest and sell it in a foreign market.

After selling the harvest for 32ECU, the travelling merchant could either share the profit with you or take all the money and run.

If the travelling merchant shares, you both get 16ECU. But if the travelling merchant takes the money and runs, then you will get $0 \mathrm{ECU}$ (the travelling merchant gets 32ECU).

However, if you give your products to the travelling merchant, you can't also trade with the local merchant. The local merchant will only get 4ECU since you are no longer their trade partner.

All your previous options are still available to you. You can keep your harvest for yourself, trade the harvest with the local merchant or let the travelling merchant take the products to the foreign market.
Keep your harvest
Trade with local merchant
Trade with the traveling merchant

Farmers' narration (periods 6 to 8) You still can keep your harvest for yourself or to trade it to the local merchant. If you keep the harvest for yourself then you will get 4ECU. If you trade with the local merchant you get 8ECU.

A new travelling merchant has approached you offering the same potential as the previous travelling merchant. This merchant can sell your harvest for a profit of 32ECU in a foreign market.

If you decide to trade with the new travelling merchant and he/she shares the profits you both get 16ECU. But if he/she takes the money and runs, you get 0 (i.e. travelling merchant gets 32ECU).

Remember, if you give your products to the travelling merchant, you can't also trade with the local merchant. The local merchant will only get 4ECU since you are no longer their trade partner. You have three options.
Keep your harvest
Trade with local merchant
Trade with the traveling merchant

Travelling merchants' narration (periods 5 to 8) when traded with You have arrived in a small county and found a farmer who is willing to let you sell the harvest on the foreign market. You can sell this harvest for 32ECU.

You successfully sold the harvest, and you can either split the profit and each one of you gets 16 ECU or you can take all the money and run.

If you take the money you will get 32ECU and the farmer will get OECU.

$$
\text { Split the profit Take the money and run }
$$

Traveling merchants' narration (periods 5 to 8) when not traded with You traveled this period but the farmer of this village decides to not trade with you. You will travel to another village to find another farmer to trade with.

$$
O K
$$

Local Merchant's narration (Period 5) You are a merchant who sells goods in a local market. You have a long-standing relationship with a farmer who often gives you his harvest to sell at the market. When the farmer gives you the harvest, each of you gets 8ECU.

The Farmer has three options: 1) Keep the product, 2) give the product to you, 3) give the product to a traveling merchant.

If farmer decides to keep the product or give it to the traveling merchant, then you will get 4ECU. If he decides to deal with you, then you both get $8 \mathrm{ECU}$. 


\section{A.1.3 The WE treatment}

Farmers' narration (periods 5) A travelling merchant has arrived in your county. Travelling merchants know different people and foreign markets. They travel all year long selling merchandise to the highest bidder. This merchant has offered to take your harvest and sell it in a foreign market.

After selling the harvest for $32 \mathrm{ECU}$, the travelling merchant could either share the profit with you or take all the money and run.

If the travelling merchant shares, you get $16 \mathrm{ECU}$, but if the travelling merchant takes the money and runs, then you will take the merchant to court.

With a probability of $1 / 2$ (one out of two times), the court finds the merchant guilty, gives you back $16 \mathrm{ECU}$, and charges the merchant 5ECU in court fees, leaving the merchant with 11ECU.

With the probability of $1 / 2$ (one out of two times), the court does not find the merchant guilty and charges you 5ECU in court fees. In this case, the travelling merchant keeps all the money.

However, if you give your products to the travelling merchant, you can't also trade with the local merchant. The local merchant will only get 4ECU since you are no longer their trade partner. All your previous options are still available to you. You can keep your harvest for yourself, trade the harvest with the local merchant, or let the travelling merchant take the products to the foreign market.
Keep your harvest
Trade with local merchant
Trade with the traveling merchant

Farmers' narration (periods 6 to 8) You still can keep your harvest for yourself or to trade it to the local merchant.

If you keep the harvest for yourself then you will get 4ECU. If you trade with the local merchant you get 8ECU. A new travelling merchant has approached you offering the same potential as the previous travelling merchant. This merchant can sell your harvest for a profit of 32ECU in a foreign market.

If you decide to trade with the new travelling merchant and he/she splits the gains from trade, you get 16ECU but if he takes the money and runs, then a court will try your case.

With a probability of $1 / 2$ (one out of two times), the court finds the merchant guilty, gives you back 16ECU, and charges the merchant 5ECU in court fees, leaving the merchant with 11ECU.

With the probability of $1 / 2$ (one out of two times), the court does not find the merchant guilty and charges you 5ECU in court fees. In this case, the travelling merchant keeps all the money.

If you give your products to the travelling merchant, you will also impact the local merchant who will only get 4ECU since you are no longer their trade partner. You have three options.
Keep your harvest
Trade with local merchant
Trade with the traveling merchant

Local Merchant's narration (Period 5) You are a merchant who sells goods in a local market. You have a long-standing relationship with a farmer who often gives you his harvest to sell at the market. When the farmer gives you the harvest, each of you gets 8ECU.

The Farmer has three options: 1) Keep the product, 2) give the product to you, 3) give the product to a traveling merchant.

If farmer decides to keep the product or give it to the traveling merchant, then you will get 4ECU. If he decides to deal with you, then you both get 8ECU.

$\mathrm{OK}$ 
Travelling merchants' narration (periods 5 to 8) You have arrived in a small county and found a farmer who is willing to let you sell the harvest on the foreign market. You can sell this harvest for 32ECU.

You successfully sold the harvest, and you can either split the profit and each one of you gets $16 \mathrm{ECU}$ or you can take all the money and run.

If you decide to take the money and run, a court will try the case. With a probability of $1 / 2$ (one out of two times), the court finds you guilty. In this case, the court charges you 5ECU in court fees so you will get 11ECU and give the farmer 's share (16ECU) back.

With a probability of $1 / 2$ (one out of two times), the court does not find you guilty, you keep all the money (32ECU), and the farmer pays 5ECU in court fees (the farmer's profit is -5ECU).

You have two options: Split the profit

Take the money and run

\section{A.1.4 The NoLM treatment's common stage}

Farmers' narration (period 1) You are a farmer in a small county. You have to work hard around the clock to harvest your products.

You can do two things with your harvest.

First, you can sell your harvest in the local market. If you sell your harvest in the local market you make 8ECU.

Second, you can keep your harvest and consume everything yourself. In this case your payoff is equal to $4 \mathrm{ECU}$.

You can either keep your harvest or sell it in the local market.

$$
\text { Keep your harvest Sell in the local market }
$$

Farmers' narration (periods 2 to 4) You have two options.

your harvest for yourself, this pays you $4 \mathrm{ECU}$, or selling your products in the local market which pays you $8 \mathrm{ECU}$.

$$
\text { Keep your harvest Sell in the local market }
$$

Traveling merchants' narration (period 1) You are a travelling merchant accustomed to dealing with different people and markets. To make your living selling merchandise, you have to travel all year long.

Farmers work hard around the clock to collect their harvest. If you travel to a village and find a farmer who is willing to trade you his harvest, you both can possibly gain from trade. But if you do not find a farmer or if the farmer is unwilling to trade with you, then you will have no opportunity to trade. Your payoff will be 4 ECU.

\section{$O K$}

Traveling merchants' narration (periods 2 to 4) You traveled this period but you were unsuccessful in finding a farmer to trade with.

$$
\text { OK }
$$

\section{A.1.5 The NoLM treatment}

Farmers' narration (period 4) A travelling merchant has arrived in your county. Travelling merchants know different people and foreign markets. They travel all year long selling merchandise to the highest bidder. 
This merchant has offered to take your harvest and sell it in a foreign market.

After selling the harvest for 32ECU, the travelling merchant could either share the profit with you or take all the money and run.

If the travelling merchant shares, you both get 16ECU. But if the travelling merchant takes the money and runs, then you will get 0ECU (the travelling merchant gets 32ECU).

All your previous options are still available to you.

You can keep your harvest for yourself (which pays you 4ECU), sell the harvest in the local market (which pays you 8ECU) or let the travelling merchant take the products to the foreign market.
Keep your harvest
Sell in the local market
Trade with the traveling merchant

Farmers' narration (periods 5 to 8) You still can keep your harvest for yourself or to sell in the local market.

If you keep the harvest for yourself then you will get 4ECU.If you sell your harvest in the local market you get $8 \mathrm{ECU}$.

A new travelling merchant has approached you offering the same potential as the previous travelling merchant. This merchant can sell your harvest for a profit of 32ECU in a foreign market.

If you decide to trade with the new travelling merchant and he/she shares the profits, you both get16ECU. But if he/she takes the money and runs you get $0 \mathrm{ECU}$ (i.e. travelling merchant gets 32ECU).

You have three options.

Keep your harvest

Sell in the local market

Trade with the traveling merchant

Traveling merchants' narration (periods 5 to 8) if engaged in long-distance trade You have arrived in a small county and found a farmer who is willing to let you sell the harvest on the foreign market. You can sell this harvest for 32ECU.

You successfully sold the harvest, and you can either split the profit and each one of you gets 16ECU or you can take all the money and run.

If you take the money you will get 32ECU and the farmer will get 0ECU. Split the profit

Take the money and run

Traveling merchants' narration (periods 5 to 8) if not engaged in long-distance trade You traveled this period but the farmer of this village decides to not trade with you.

You will travel to another village to find another farmer to trade with.

$O K$

\section{A.2 Norm elicitation and belief elicitation}

The beginning In the following experiment, you will complete two tasks. At the end of the experiment, the computer will select one of those two tasks at random, with each task equally likely to be chosen. You will receive your earnings from that task plus your $\$ 7$ show-up payment.

Please read the instructions carefully, as your payments depend on how well you understand them.

On the following screens, you will read descriptions of a situation. These descriptions correspond to a situation in which one person must make a decision. For each situation, you will be given a description of the decision faced by the person. This description will include a set of possible actions available to the person.

After you read the description of the decision, you will be asked to evaluate the actions available and to decide, for each of the possible actions, whether taking that action would be "socially appropriate" and "consistent with moral or proper social behavior" or "socially inappropriate" and "inconsistent with 
moral or proper social behavior." By socially appropriate, we mean behavior that most people agree is the "correct" or "ethical" thing to do. Another way to think about what we mean is that if the person were to select a socially inappropriate choice, then someone else might be angry at the person for doing so.

In each of your responses, we would like you to answer as truthfully as possible, based on your opinions of what constitutes socially appropriate or socially inappropriate behavior.

To give you an idea of how the experiment will proceed, we will go through an example and show you how you will indicate your responses. On the next screen you will see an example of a situation.

Click OK when you are ready to go on.

$\mathrm{OK}$

Example situation "Individual A" is at a café. While there, Individual A notices that someone has left a wallet at one of the tables. Individual A must decide what to do. Individual A has four possible choices: take the wallet, ask others nearby if the wallet belongs to them, leave the wallet where it is, or give the wallet to the bartender.

Individual A can choose only one of these four options. Below is the list of these actions. For each of the actions, please indicate whether you believe choosing that option is very socially inappropriate, somewhat socially inappropriate, somewhat socially appropriate, or very socially appropriate. To indicate your response, please click on the corresponding cell.

Please make sure you make an assessment for each possible choice in the below list.

In what follows, you will be asked to assess the appropriateness of actions in the situation above. For the proposed action please indicate the extent to which you believe taking that action would be "socially appropriate" and "consistent with moral or proper social behavior" or "socially inappropriate" and "inconsistent with moral or proper social behavior." By socially appropriate we mean behavior that most people agree is the "correct" or "ethical" thing to do.

Take the wallet

Very socially inappropriate

Somewhat socially appropriate

Leave the wallet where it is

Very socially inappropriate

Somewhat socially appropriate

Give the wallet to the bartender

Very socially inappropriate

Somewhat socially appropriate

Ask others nearby if the wallet belongs to them

Very socially inappropriate

Somewhat socially appropriate
Somewhat socially inappropriate

Very socially appropriate

Somewhat socially inappropriate

Very socially appropriate

Somezhat socially inappropriate

Very socially appropriate

Somewhat socially inappropriate

Very socially appropriate

On the next screen is a narration from a set of experiments that were conducted here a year ago. Please read them carefully so you understand the decision that other participants were asked to make. At the 
end of the narration, we will ask you to evaluate how socially appropriate each of these possible actions is. Then we will select one of the actions at random; each action is equally likely to be selected.

For the action selected, we will determine which evaluation was selected by the most people here today.

If your evaluation of that action is the same as the most common response given by others, you will receive an additional $\$ 8$.

This amount will be paid to you, in cash, at the conclusion of the experiment.

For instance, if we were to select the example situation from the last screen and the possible choice "Leave the wallet where it is," and if your response had been "somewhat socially inappropriate," then you would receive $\$ 8$, in addition to the $\$ 7$ participation fee, only if this was the response selected by most other people in today's session. Otherwise you would receive only the $\$ 7$ participation fee.

Your payment in this task depends only on whether your response corresponds to the most common evaluation of the chosen action by people in this room and DOES NOT depend on the decisions made by the participants in the experiment from a year ago.

Please click OK when you are ready to go on.

OK

Narration You are a farmer in a small county. You have to work hard around the clock to harvest your products.

You can do three things with your harvest.

First, you can give your harvest to a local merchant who sells some of it for you. This is a long-standing relationship, and each time you deal with the local merchant, both of you make $\$ 4$.

Second, You can keep your harvest and consume it yourself. If you choose this option your gain is equal to $\$ 2$.

[The farmer had to choose between trading with the local merchant and keeping the harvest to himself for four periods in a row. Almost all farmers chose to trade with the local merchant. Then, in the fifth period, the following narration was observed.]

A traveling merchant has arrived in your county. Traveling merchants know different people and foreign markets. They travel all year long selling merchandise to the highest bidder.

This merchant has offered to take your harvest and sell it in a foreign market.

After selling the harvest for $\$ 16$, the traveling merchant could either share the profit with you or take all the money and run.

If the traveling merchant shares, you both get $\$ 8$. But if the traveling merchant takes the money and runs, then you will get $\$ 0$ (the traveling merchant gets $\$ 16$ ).

However, if you give your products to the traveling merchant, you can't also trade with the local merchant. The local merchant will only get $\$ 2$ since you are no longer his/her trade partner.

Now based on the narration that you have read, we ask you three questions. You will be asked to assess the appropriateness of each of the possible actions in the situation above. For each possible action, please indicate the extent to which you believe taking that action would be "socially appropriate" and "consistent with moral or proper social behavior" or "socially inappropriate" and "inconsistent with moral or proper social behavior." By socially appropriate we mean behavior that most people agree is the "correct" or "ethical" thing to do.

Appropriateness Task Below, you need to provide your evaluation of the social appropriateness of 3 actions available to the farmer. At the end of the experiment, one of these actions will be chosen at random. Remember, if you give the same response as that most frequently given by other participants 
of today's experiment, then you will receive an additional $\$ 8$ for this task, which will be paid if Task 1 is chosen for payment. When you finish Task 1, please wait quietly for others to finish.

\title{
ACTION 1
}

How socially appropriate/inappropriate is it for the farmer to trade with the local merchant (rather than the travelling merchant)?

$$
\begin{gathered}
\text { Very socially inappropriate } \\
\text { Somewhat socially appropriate }
\end{gathered}
$$

\author{
Somewhat socially inappropriate \\ Very socially appropriate
}

\section{ACTION 2}

How socially appropriate/inappropriate is it for the farmer to keep the harvest (i.e. not trade with anyone)?
Very socially inappropriate
Somewhat socially appropriate
Somewhat socially inappropriate
Very socially appropriate

\section{ACTION 3}

How socially appropriate/inappropriate is it for the farmer to trade with the traveling merchant (rather than the local merchant)?

$$
\begin{aligned}
& \text { Very socially inappropriate } \\
& \text { Somewhat socially appropriate }
\end{aligned}
$$

\author{
Somewhat socially inappropriate \\ Very socially appropriate
}

Narration Below is additional narration from last year's experiment described above; as before, the bolded text was not included in the original narration, but you may find it useful for making your decisions. This narration shows you the experiment from the point of view of the participant in the role of the "travelling merchant".

You are a travelling merchant accustomed to dealing with different people and markets. To make your living selling merchandise, you have to travel all year long. Farmers work hard around the clock to collect their harvest. If you travel to a village and find a farmer who is willing to trade you his harvest, you both can possibly gain from trade. But if you do not find a farmer or if the farmer is unwilling to trade with you, then you will have no opportunity to trade. Your payoff will be $\$ 2$.

For 4 periods, the travelling merchant is travelling and unable to find anyone with whom he might trade, but this information is known only to him. In the 5th period, he comes upon a small county with the farmer. If the farmer chose to "trade with the travelling merchant", he saw the following additional narration:

You have arrived in a small county and found a farmer who is willing to let you sell the harvest on the foreign market. You can sell this harvest for $\$ 16$.

You successfully sold the harvest, and you can either split the profit and each one of you gets $\$ 8$ or you can take all the money and run. If you take the money you will get $\$ 16$ and the farmer will get $\$ 0$.

Now based on the narration that you have read, we ask you one question.

Please click OK when you are ready to go on.

$\mathrm{OK}$ 
In task 2, considering the narration you just read, what is the probability that the traveling merchant shares the profit (rather than taking the money for himself) assuming that a farmer chooses to trade? You choose a number between 0 and 100, where " 0 " means you think the merchant would share the profits 0 out of 100 times, and 100 means you think the merchant would share 100 out of 100 times.

Before answering the above question read the following instructions.

Payment to this question is according to the following process:

After you choose a probability estimate between 0 and 100, the computer randomly picks a number " $R$ ", also between 0 and 100, with each number being equally likely. If the number that computer picked is bigger than your probability, then, the computer pays you $\$ 8$ with a probability " $R$ " and $\$ 0$ with the probability "100-R".

If, instead, the probability that you choose is bigger than the random number chosen by the computer, then your payoff will be based on the actual probability of sharing that we observed in last year's experiments. That is, if we assume that the average probability of sharing was " $\mathrm{K}$ " in the last year's experiments, you will get $\$ 8$ with a probability of " $\mathrm{K}$ " and $\$ 0$ with a probability "1- $\mathrm{K}$ ".

This process is designed in a way that makes reporting your true beliefs the best possible strategy for you. Here's why:

Example 1: Suppose you report a probability higher than your actual beliefs:

Let's assume that you think the probability of sharing, in last year's experiment, is 30 (out of 100) but you report 60 (out of 100). If the computer draws the number $R=50$, then your chance of winning $\$ 8$ will depend on the actual chance of a merchant choosing to share (which you think is 30 out of 100), and your chance of winning $\$ 0$ will be based on the actual chance of a merchant choosing to take the money and run (which you think is 70 out of 100). If you had reported your true belief of 30 instead of 60, then your chance of winning the $\$ 8$ would be based on a lottery that pays $\$ 8$ with probability $R=50$ (out of 100) and pays $\$ 0$ with probability 100 - $R=50$ (out of 100). Thus your odds of winning are best if you report truthfully, rather than reporting beliefs that are higher than your actual beliefs.

Example 2: Suppose you report a probability lower than your actual beliefs:

Let's assume that you think the probability of sharing, in the last year experiment, is 60 (out of 100) but you report 30 (out of 100). If the computer draws $R=50$, then your chance of winning $\$ 8$ will depend on a lottery that pays $\$ 8$ with probability $R=50$ (out of 100 ) and pays $\$ 0$ with probability $100-R=50$ (out of 100). If you had reported your true beliefs of 60 instead of 30, then your chance of winning the $\$ 8$ would be based on the actual chance of a merchant choosing to share (which you think is 60 out of 100 ), and your chance of winning $\$ 0$ will be based on the actual chance of a merchant choosing to take the money and run (which you think is 40 out of 100). Thus your odds of winning are best if you report truthfully, rather than reporting beliefs that are higher than your actual beliefs.

Please type your best estimate of the probability that a travelling merchant shared the profit with a farmer in the experiment (that is, if you think a traveling merchant shared 67 times out of 100 then write 67 in the box).

OK 


\section{A.3 The Triad Task}

The beginning At this stage of the experiment you will be asked a number of questions. There is no right or wrong answer. Please answer them as best you can.

In the following lists, among the three things listed together, please indicate which two of the three are most closely related.

\begin{tabular}{lccc}
\hline 1. & Seagull & Sky & Dog \\
2. & Black & White & Blue \\
3. & Doctor & Teacher & Homework \\
4. & Apple & Orange & Pear \\
5. & Shoes & Boots & Slippers \\
6. & Train & Bus & Tracks \\
7. & Computer monitor & Antenna & Television \\
8. & Hospital & Bank & Cinema \\
9. & Carrot & Eggplant & Rabbit \\
10. & Cloud & Wind & Rain \\
11. & Panda & Banana & Monkey \\
12. & Shirt & Hat & Pants \\
13. & Kite & Basketball & Tennis \\
14. & Farmer & Corn & Bread \\
15. & Shampoo & Hair & Beard \\
16. & Bridge & Tunnel & Highway \\
17. & Piano & Violin & Guitar \\
18. & Child & Man & Woman \\
19. & Postman & Policeman & Uniform \\
20. & Letter & Stamp & Postcard \\
\hline
\end{tabular}

(In the experiment, subjects saw the questions one by one. The questions used to compute the I/C score are 1,3,6,7,9,11,14,15. For example, in (1) a collectivist would choose \{seagull, sky\}, focusing on a holistic relationship between a bird and the sky, while an individualist would choose \{seagull, dog\}, focusing on the category "animal".)

The end Now you will go to the next phase. In this phase of the experiment you will be assigned a certain role in a narrative. Then you will make decisions that affect the narrative you observe as well as the narrative observed by others. Together all players' decisions will determine their payoffs. Please read the text carefully. Be aware that outcomes may depend on other player's action as well. The narratives are simple, and if you follow them carefully, you may earn a considerable amount of money which will be paid to you in cash at the end of the experiment.

This phase will last for several periods, and you will be paid the sum of your earnings from all periods.

Every 12 experimental currency unit (henceforth ECU) will be converted to 1 CAD. 


\section{A.4 Risk preference elicitation instructions}

In the questions that follow, you are going to be asked to make ten decisions. Each decision will be between Option A and Option B. One of the ten choices you make will be randomly selected to determine your earnings for this part of the experiment.

\begin{tabular}{llc}
\hline & \multicolumn{1}{c}{ Options } & Your Choice \\
\hline A & B & A or B \\
\hline 1 or $\$ 3$ each with probability 1/2 & $\$ 0.1$ with probability $9 / 10$ or $\$ 4$ with probability $1 / 10$ & A or B \\
$\$ 1$ or $\$ 3$ each with probability $1 / 2$ & $\$ 0.1$ with probability $8 / 10$ or $\$ 4$ with probability $2 / 10$ & A or B \\
$\$ 1$ or $\$ 3$ each with probability $1 / 2$ & $\$ 0.1$ with probability $7 / 10$ or $\$ 4$ with probability $3 / 10$ & A or B \\
$\$ 1$ or $\$ 3$ each with probability $1 / 2$ & $\$ 0.1$ with probability $6 / 10$ or $\$ 4$ with probability $4 / 10$ & A or B \\
$\$ 1$ or $\$ 3$ each with probability $1 / 2$ & $\$ 0.1$ with probability $5 / 10$ or $\$ 4$ with probability $5 / 10$ & or B \\
$\$ 1$ or $\$ 3$ each with probability $1 / 2$ & $\$ 0.1$ with probability $4 / 10$ or $\$ 4$ with probability $6 / 10$ & A or B \\
$\$ 1$ or $\$ 3$ each with probability $1 / 2$ & $\$ 0.1$ with probability 3/10 or $\$ 4$ with probability $7 / 10$ & A or B \\
$\$ 1$ or $\$ 3$ each with probability $1 / 2$ & $\$ 0.1$ with probability $2 / 10$ or $\$ 4$ with probability $8 / 10$ & A or B \\
$\$ 1$ or $\$ 3$ each with probability $1 / 2$ & $\$ 0.1$ with probability $1 / 10$ or $\$ 4$ with probability $9 / 10$ & A or B \\
$\$ 1$ or $\$ 3$ each with probability $1 / 2$ & $\$ 0.1$ with probability $0 / 10$ or $\$ 4$ with probability $10 / 10$ & \\
\hline
\end{tabular}




\section{B Additional Analysis}

\section{B.1 Risk Preferences}

Figure B1 shows the relative frequency of the safe choice for each pair of lotteries. As is often the case in multiple price list elicitations, our subjects are risk averse on average. As is also common, we observe a small set of subjects whose preferences are inconsistent with EU.

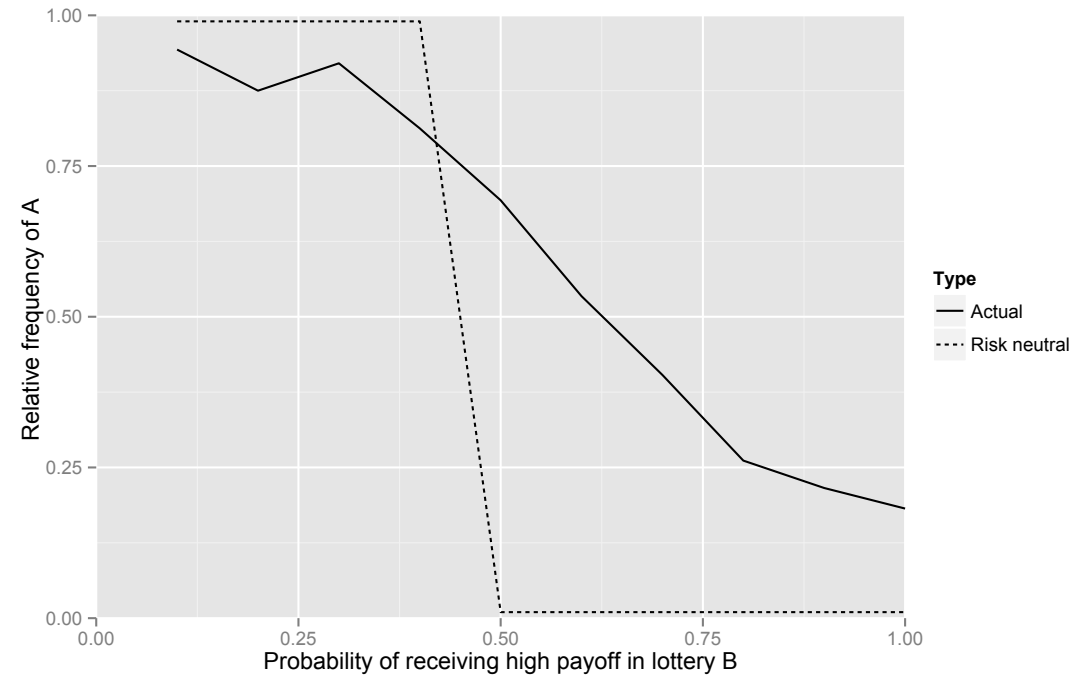

Figure B1: The distribution of choices in the risk preference elicitation. The solid line plots the data, and the dashed line plots the risk-neutral, expected utility maximizing choices.

\section{B.2 Norm Elicitation and Belief Elicitation}

As described before, farmers, in each round of treatment, could "keep the harvest", "trade with the local merchant", or "trade with the traveling merchant". In the norm elicitation task, we ask subjects to rate each action on a four-point scale. That is, "very inappropriate", " somewhat inappropriate", " somewhat appropriate", and "very appropriate". Furthermore, subjects would have got paid only if their answers corresponded to the most frequent response of others in the room .

(1)

(2)

(3)

Keep the harvest Local merchant Traveling merchant

\begin{tabular}{lccc}
\hline I/C Score & $\begin{array}{c}-0.043 \\
(0.036)\end{array}$ & $\begin{array}{c}0.036 \\
(0.039)\end{array}$ & $\begin{array}{c}-0.020 \\
(0.037)\end{array}$ \\
\hline \hline Observations & 29 & 29 & 29 \\
\hline Standard errors in parentheses. ${ }^{*} \mathrm{p}<0.1,{ }^{* *} \mathrm{p}<0.05,{ }^{* * *} \mathrm{p}<0.01$. &
\end{tabular}

Table B1: Regression Analysis of Appropriateness

Figures B2, B3, and B4, display the frequency of the subjects' choice for each one of the farmer's actions. To investigate whether the injunctive social norms, in the context of this experiment, have any 
correlation with the individualism and collectivism, we estimate the effect of I/C score on the subjects' choice employing ordered logit regressions. Table B1 shows the results of these regressions. Columns 1, 2, and 3 report the regressions for the "keep the harvest", "trade with the local merchant", and "trade with the traveling merchant", respectively.

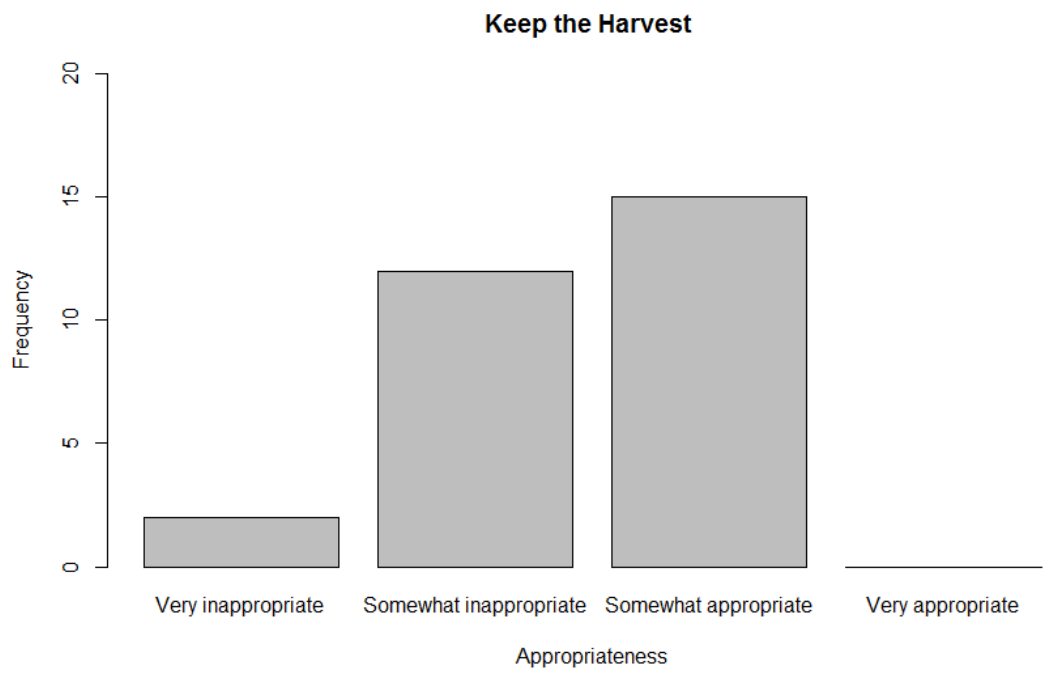

Figure B2: Perceived Appropriateness of Keeping the Harvest.

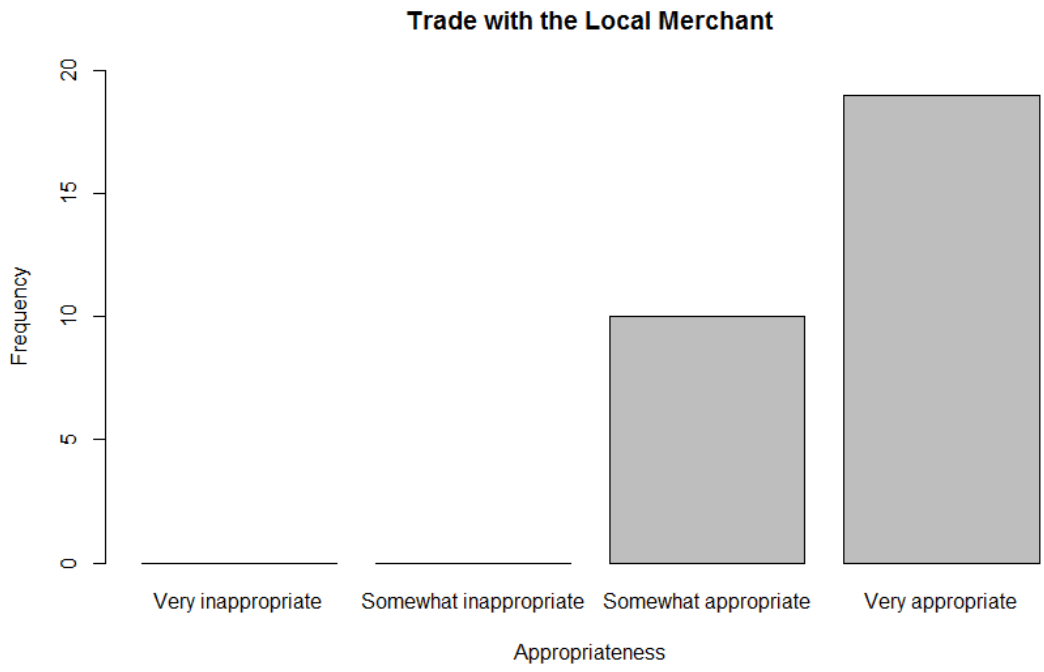

Figure B3: Perceived Appropriateness of Trading with the Local Merchant.

The payment method is designed to truthfully capture what subjects perceived to be the social norm and not what they would prefer to do individually in such a situation. Since we observe no significant correlation between I/C score and the perceived injunctive social norms across the farmer's actions, we may only claim that subjects share similar normative beliefs about what ought to be done. However, what they would actually do may vary with dispositions to individualism and collectivism. 


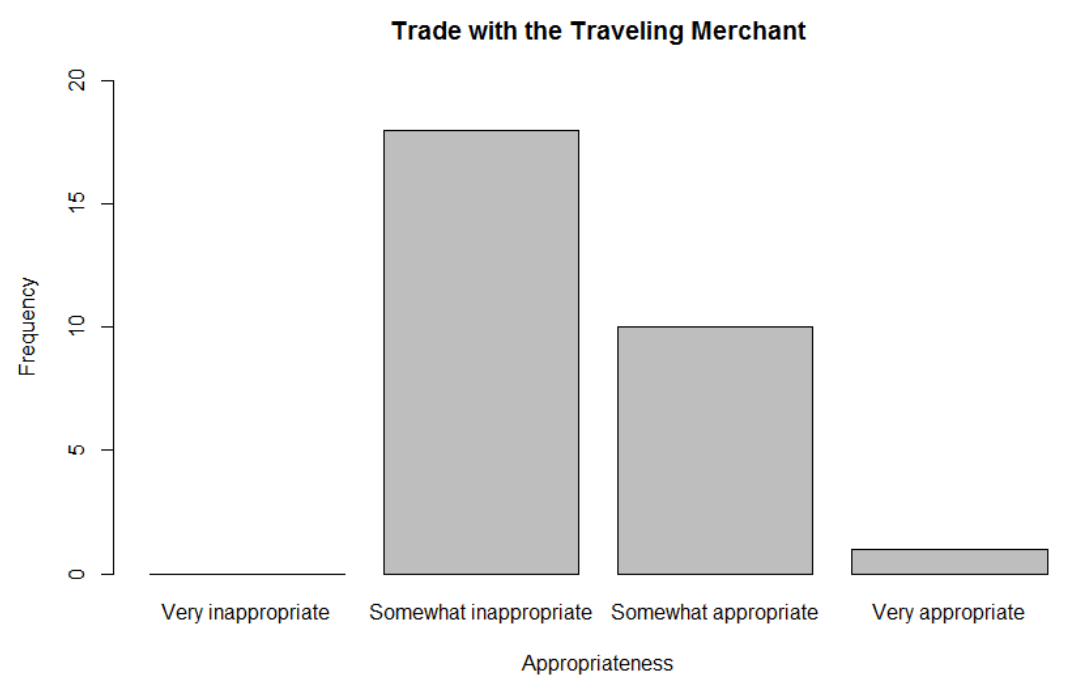

Figure B4: Perceived Appropriateness of Trading with the Traveling Merchant.

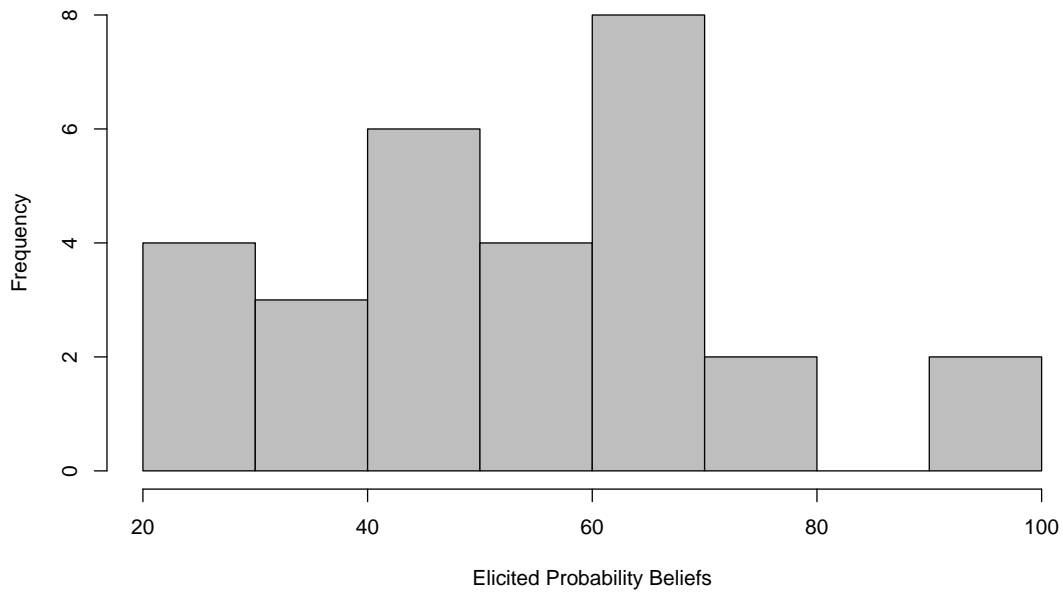

Figure B5: Histogram of elicited probability beliefs.

Figure B5 reports the histogram of elicited probability beliefs. In our sample, the range of these elicited beliefs was from $20 \%$ to $100 \%$. We observe a positive significant correlation between I/C score and elicited probability beliefs (Spearman's $\rho=0.41, p-$ value $=0.03$ ) indicating that individualist farmers are more optimistic regarding traveling merchants' cooperation than their collectivist counterparts.

\section{B.3 Traveling Merchants' Behavior}

In the subgame perfect Nash equilibrium of all four treatments, a payoff maximizing traveling merchant cheats the farmer with probability 1 ; however, we observe substantial reciprocation in all treatments: the merchant cheats in only $14 / 33(42 \%)$ instances in the NE treatment, $19 / 32(59 \%)$ instances in the WE treatment, $16 / 42(38 \%)$ instances in the SE treatment, and $14 / 35(40 \%)$ in the NoLM treatment. This is 
consistent with two decades of the experimental evidence revealing positive reciprocity in trust games (e.g. Johnson and Mislin, 2011).

\begin{tabular}{|c|c|c|}
\hline & $\begin{array}{c}(1) \\
\text { Cheat }_{t}\end{array}$ & $\begin{array}{c}(2) \\
\text { Cheat }_{t}\end{array}$ \\
\hline I/C Score & $\begin{array}{c}0.096 \\
(0.315)\end{array}$ & $\begin{array}{l}1.873^{* *} \\
(0.832)\end{array}$ \\
\hline Weak Enforcement & $\begin{array}{c}0.256^{* * *} \\
(0.092)\end{array}$ & $\begin{array}{r}0.972^{* * *} \\
(0.215)\end{array}$ \\
\hline Strong Enforcement & $\begin{array}{c}0.033 \\
(0.075)\end{array}$ & $\begin{array}{l}0.588^{* *} \\
(0.252)\end{array}$ \\
\hline No Local Merchant & $\begin{array}{c}0.074 \\
(0.140)\end{array}$ & $\begin{array}{l}0.652^{* *} \\
(0.256)\end{array}$ \\
\hline $\mathrm{WE} \times \mathrm{I} / \mathrm{C}$ & & $\begin{array}{c}-2.263^{* * *} \\
(0.870)\end{array}$ \\
\hline $\mathrm{SE} \times \mathrm{I} / \mathrm{C}$ & & $\begin{array}{l}-1.851^{*} \\
(0.967)\end{array}$ \\
\hline $\mathrm{NoLM} \times \mathrm{I} / \mathrm{C}$ & & $\begin{array}{r}-1.940^{* *} \\
(0.868)\end{array}$ \\
\hline Intercept & $\begin{array}{c}0.328^{* * *} \\
(0.114)\end{array}$ & $\begin{array}{l}-0.206 \\
(0.203)\end{array}$ \\
\hline Observations & 142 & 142 \\
\hline $\mathrm{R}^{2}$ & 0.02 & 0.08 \\
\hline
\end{tabular}

Table B2: Regression Analysis of Cheating by Traveling Merchants

Although our interpretation of the individualism/collectivism distinction does not have direct implications for traveling merchants' behavior, we look for any behavioral pattern that emerges in the experiment. Note that, due to the role assignment rule, which assigned the most and least collectivistic subjects to the role of the Farmer, the distribution of traveling merchants' I/C scores is compressed and away from the extremes. In fact, in the NE treatment there is no traveling merchant with individualistic tendencies (that is, I/C scores $\leq 0.5$ for all traveling merchants). Figure B6 displays histograms of the I/C distribution for traveling merchants in each treatment.

Nevertheless, for completeness, we report regression analysis of the determinants of the decision to cheat. We restrict attention to the observations in which the farmer chose long-distance trade. The dependent variable takes a value of 1 when the merchant cheated the farmer and 0 otherwise. In our first specification, the independent variables include a constant term, the merchant's I/C score, and treatment dummies. In a second specification, we include interactions between the treatments and I/C score. We include random effects for each subject to control for repeated observations, and we cluster standard errors at the session level. Table B2 reports GLS regression results. In column (1), we observe no effect of $\mathrm{I} / \mathrm{C}$ score on cheating, though there is more cheating overall in the WE treatment. Perhaps this is driven by the weakening of the cooperative signal sent by the farmer's trade decision. In column (2), we observe a positive and significant coefficient on the I/C score among those in the NE treatment. However, due to the compressed distribution, this reflects differences only within subjects who were somewhat collectivistic. In the other treatments, where we observe traveling merchants with individualistic tendencies, 
(a) NE

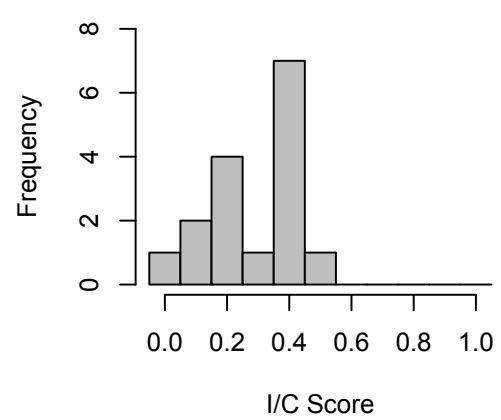

(c) SE

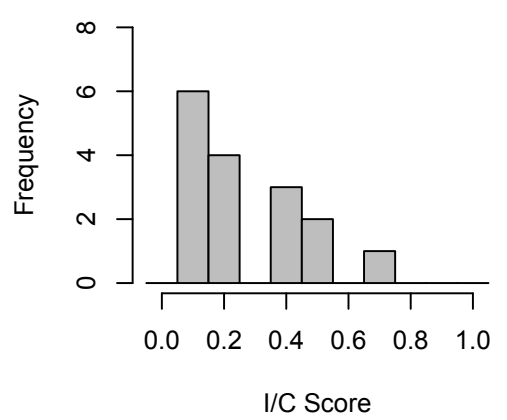

(b) WE

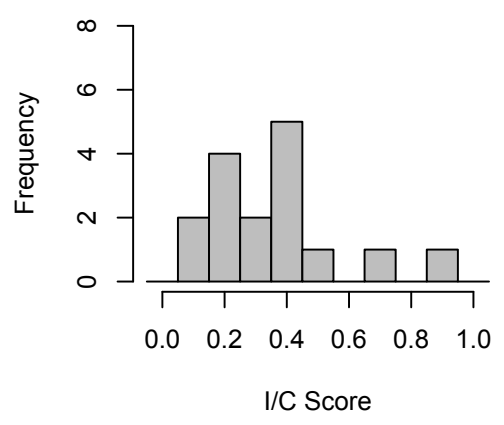

(d) NoLM

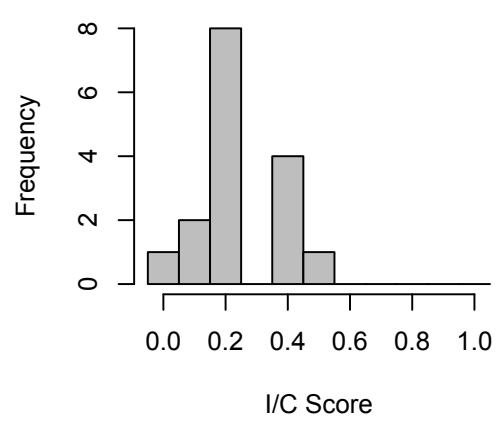

Figure B6: Histograms of traveling merchants' I/C scores, by treatment. Each panel displays the data for one treatment. Note that the distribution is compressed away from the extremes; in particular the sample contains very few individualists.

this effect is offset. Wald tests cannot reject the null hypothesis that the sum of the coefficient on the I/C score and the I/C treatment interaction is equal to 0 for any treatment (p-values $=0.12,0.96$ and 0.79 for the WE, SE and NoLM treatments, respectively).

In previous experiments, to alleviate the problem of cheating, different formal enforcement mechanisms have been incorporated into the trust game. In general, these formal enforcement mechanisms are either imposed by the second party (that is, player $1 /$ the "farmer" in the trust game) or by a third party (that is, a contract enforcement/court system) ${ }^{12}$. Considering second party enforcement, one possibility is to add a retaliation opportunity for player 1 after being cheated (Smith and Wilson, forthcoming) or to let player 1 credibly threaten player 2 with a fine ex ante which will be imposed in case of cheating (Fehr and Rockenbach, 2003; Fehr and List, 2004). Interestingly, both of these two methods led to increased cheating by player 2 . Bohnet et al. (2001) add a court with different enforcement power to the trust game. They find that cheating occurs less often in the weak and strong court system treatment compare to the medium enforcement power. This is consistent with our findings which show that cheating occurred significantly more often in the WE treatment than the NE, SE, and NoLM treatments.

\footnotetext{
${ }^{12}$ Third party enforcement is mainly imposed through a court that probabilistically punishes non-sharing behavior. Fehr and Fischbacher (2004), however, used human third party enforcement in both a dictator and prisoner's dilemma game. They find that human third party enforcement punishes selfish behavior roughly $60 \%$ of time at a cost to herself and therefore encourages sharing/cooperation.
} 